\title{
Iron availability regulates growth, photosynthesis, and production of ferredoxin and flavodoxin in Antarctic sea ice diatoms
}

\author{
Andrew Pankowski ${ }^{1,2}$, Andrew McMinn ${ }^{1, *}$ \\ ${ }^{1}$ Institute of Antarctic and Southern Ocean Studies, University of Tasmania, Private Bag 77, Hobart, Tasmania, Australia \\ ${ }^{2}$ Present address: Department of Environment, Water, Heritage and Arts, King Edward Terrace, Parkes, ACT 2600, Australia
}

\begin{abstract}
Iron availability affects the growth of not only phytoplankton, but also sea ice diatoms. Iron availability had a clear effect on the growth rates of Fragilariopsis cylindrus and F. curta. Maximum growth rates were $0.57 \mathrm{~d}^{-1}$ for F. cylindrus and $0.28 \mathrm{~d}^{-1}$ for $F$. curta; $K_{\mathrm{m}}$ (half-saturation growth constant) was $0.51 \times 10^{-12}$ and $1.3 \times 10^{-12} \mathrm{M}$ for F. cylindrus and F. curta, respectively. For both $F$. cylindrus and $F$. curta, $F_{\mathrm{v}} / F_{\mathrm{m}}$ (quantum yield of fluorescence) was highest and lowest for the cultures grown with the highest and lowest concentrations of iron, respectively. For both species there was also a reduction in both $\mathrm{rETR}_{\max }$ (maximum relative electron transfer rate) and $\alpha$ (photosynthetic efficiency) with decreasing iron concentration. For $F$. cylindrus grown with the least iron, rETR $_{\max }$ was half of the iron-replete value, while $\alpha$ was reduced by $65 \%$. Changes in $E_{\mathrm{k}}$ (light-adaptation parameter) were not well defined. Immunoassays were developed for the proteins ferredoxin and flavodoxin in Antarctic pack ice. Iron availability had different effects on the expression of flavodoxin and ferredoxin in the 2 Fragilariopsis species tested. Cultures of F. cylindrus grown at high iron concentration produced predominantly ferredoxin, with a small amount of flavodoxin. Ferredoxin was sequentially replaced by flavodoxin for cultures grown with less iron, although the response was not a simple switch from one protein to the other. The ability to produce ferredoxin is apparently absent in F. curta, with relatively constant levels of flavodoxin produced at all iron concentrations. These results strongly imply that the presence of flavodoxin alone cannot be used as evidence of ironlimited growth.
\end{abstract}

KEY WORDS: Antarctic $\cdot$ Sea ice $\cdot$ Iron $\cdot$ Ferredoxin $\cdot$ Flavodoxin $\cdot$ Microalgae Resale or republication not permitted without written consent of the publisher

\section{INTRODUCTION}

It is now well-established that iron plays a key role in regulating phytoplankton biomass, primary production, growth rates and community composition in the Southern Ocean (Boyd et al. 2007). Iron concentrations in the open-ocean areas of the Southern Ocean are extremely low, regularly $<0.2 \mathrm{nmol} \mathrm{kg} \mathrm{kg}^{-1}$, compared

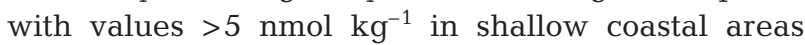
(Martin et al. 1990). But despite the numerous studies directed towards elucidating the role of iron in the Southern Ocean, there is very little information avail- able on the response of individual Southern Ocean algal species to iron limitation. Timmermans et al. $(2001 \mathrm{a}, \mathrm{b})$ studied the effects of iron on 2 Antarctic diatoms, Chaetoceros brevis and C. dichaeta, grown in both natural seawater amended with iron (without excess chelator), as well as in EDTA-buffered seawater. These investigators found clear differences in the iron requirements of the 2 species. The smaller species, C. brevis, was able to achieve rapid rates of growth at low iron concentrations and with low light. In contrast, the results for $C$. dichaeta suggested that for this species to bloom it required relatively high iron concentra- 
tions, high light intensities and a long photoperiod. Timmermans et al. (2004) studied growth rates of large Southern Ocean diatoms to determine growth kinetics and macronutrient consumption of these organisms in relation to iron availability. Van Oijen et al. (2004) also examined $C$. brevis under low iron conditions and high and low light; among their findings were that iron limitation led to reduced pigment content, decreases in light absorption and a decrease in quantum yield. They also observed large decreases in storage carbohydrates and increased susceptibility to photoinhibition.

Similar studies on Antarctic sea ice diatoms are lacking. Although it is doubtful that any algal species can be designated exclusively a 'sea ice species', Fragilariopsis curta (Grunow), F. cylindrus (Van Heurck) and Phaeocystis antarctica (Karsten) have been identified as 3 organisms that dominate pack ice assemblages (Lizotte 2001).

An estimated $80 \%$ of the iron within the cells of eukaryotic marine algae is bound within prosthetic groups of chloroplast electron transport proteins (Raven 1990). When the rate of iron uptake from the environment is insufficient to meet the demand for cell division, phytoplankton cells reduce their cellular quota for iron in an attempt to maintain growth at maximum rates (Sunda \& Huntsman 1995, 1997). Mechanisms thought to be responsible for the lowering of iron quotas under iron stress include a general decrease in the number of photosynthetic units (Sunda \& Huntsman 1997), decreased synthesis of specific iron-containing proteins (Greene et al. 1992) and substitution of iron-containing proteins for functionally equivalent proteins without iron, such as the replacement of ferredoxin for flavodoxin (La Roche et al. 1993, 1995).

Considerable differences in iron use efficiencies have been observed between different algal species. One of the most striking observations is the much lower (up to 8-fold) iron requirements of oceanic species compared to coastal species (Brand 1991, Sunda \& Huntsman 1995), although surface area normalised uptake rates of coastal and oceanic species are similar (Sunda \& Huntsman 1995). Iron transport rates in all marine algae are constrained by limits imposed by diffusion and ligand exchange kinetics and by the number of transport molecules that can fit in a unit area of cell membrane (Morel et al. 1991). Because oceanic algal species have not been able to develop more efficient uptake systems, evolutionary pressure has forced oceanic species to either become smaller or reduce their cellular requirements for iron (Sunda \& Huntsman 1995). The rearrangement of photosynthetic architecture through the reduction of the ratio of Photosystem I (PSI) to Photosystem II (PSII) has been identified as one mechanism employed by oceanic species to reduce their demand for iron (Strzepek \& Harrison 2004). Other strategies utilised by oceanic microalgae to reduce their iron quota remain unknown, but are to likely to involve the replacement of iron-containing catalysts with functionally equivalent proteins that do not contain iron, and minimisation or avoidance of biochemical pathways that require iron (Sunda \& Huntsman 1995).

It can be assumed that algal species that thrive in pack ice are well adapted to the conditions that exist in this habitat. The Antarctic pack ice is characterised by strong gradients of temperature, light, salinity and nutrient supply (McMinn et al. 1999, Brierley \& Thomas 2002, Arrigo 2003, Thomas \& Papadimitriou 2003). These conditions may have placed significant evolutionary pressure on these organisms to develop an efficient metabolism in regard to iron.

Here we describe the effects of iron limitation on Fragilariopsis cylindrus and F. curta, 2 diatoms that dominate Antarctic pack ice. Iron stress is considered any concentration of Fe that results in a lower growth rate, and the half-saturation constants for growth in relation to iron availability are determined for these organisms. Physiological and biochemical responses to iron limitation are also examined. Particularly, relationships between ferredoxin and flavodoxin expression, iron availability and other biochemical/ physiological responses to reduced iron supply are determined. This is done in order to assess the usefulness of ferredoxin and flavodoxin as markers for iron availability in these organisms.

\section{MATERIALS AND METHODS}

All cultures examined in the present study were isolated from melted sea ice collected in the Mertz Glacier region (63 to $66^{\circ} \mathrm{S}, 143$ to $148^{\circ} \mathrm{E}$ ) of the Southern Ocean during Voyage 1 of the RS 'Aurora Australis' in October to November 2002 (Pankowski \& McMinn 2009).

Fragilariopsis cylindrus and F. curta were grown in $250 \mathrm{ml}$ (for acclimation) or $500 \mathrm{ml}$ (final experiments) polycarbonate jars with polypropylene lids (Technoplas). Culture-ware and any material that came in contact with growth medium was soaked in $0.01 \%$ Triton $\mathrm{X} 100$ in $>18.2 \mathrm{M} \Omega$ resistivity Milli-Q water for $24 \mathrm{~h}$, and then rinsed with 5 rinses of Milli-Q water. It was then soaked overnight in $1 \mathrm{~N} \mathrm{HCl}$ (Mallinkrodt AR select), followed by another 5 rinses with Milli-Q water. All rinsing and subsequent handling of plasticware was done in a trace-metal-clean laminar flow hood. For sterilisation, bottles or jars were filled with Milli-Q water, lightly capped, placed in polyethylene 
zip-lock bags and heated in a domestic $700 \mathrm{~W}$ microwave oven to boiling point, then for a further $10 \mathrm{~min}$.

Media for culturing was prepared from natural seawater collected from the Mertz Glacier region $\left(66^{\circ} \mathrm{S}\right.$, $147^{\circ} \mathrm{E}$ ) of the Southern Ocean in November 2001 during Voyage 1 of the RV 'Aurora Australis'. Water was pumped from beneath an ice flow through a hole cut with a SIPRE ice corer. The pumping system consisted of polyethylene tubing connected to a peristaltic pump with a short length of silicone tubing. A $0.45 \mu \mathrm{m}$ polycarbonate (Osmonics) membrane housed in a polypropylene inline filter housing was used to filter the water before being collected in a polycarbonate carboy. All components of the pumping system were cleaned as described for the culture-ware. Prior to collecting water, the pumping system and carboys were flushed with 51 of seawater. The collected seawater was stored in the dark at $4^{\circ} \mathrm{C}$ for $\sim 1 \mathrm{yr}$ before being used in the experiment. Measurement of dissolved iron in the seawater by flow injection analysis showed that levels were sub-nanomolar (A. Bowie pers. comm.) and therefore insignificant compared to the levels added when preparing the trace-metalbuffered media.

Seawater from the 201 carboys was sterilised by passing it through a $0.2 \mu \mathrm{m}$ acid-cleaned capsule filter (Sartorius Sartobran 300). From the filter it was dispensed into trace-metal-clean and sterile 11 polycarbonate bottles. Media composition was based on that of AQUIL (Price et al. 1989). To each bottle was added nitrate $(300 \mu \mathrm{M})$, phosphate $(10 \mu \mathrm{M})$ and silicate $(100 \mu \mathrm{M})$ from stocks which had been passed through a Chelex column to remove contaminating trace metals (Morel et al. 1979). A combined vitamin stock was then added. A trace-metal mixture (without iron) was combined with EDTA (100 $\mu \mathrm{M}$ final concentration) before being added to the media. Final trace-metal concentrations were $19.6 \mathrm{nM}$ for $\mathrm{Cu}, 121 \mathrm{nM}$ for $\mathrm{Mn}, 80 \mathrm{nM}$ for Zn, $10 \mathrm{nM}$ for Co, $100 \mathrm{nM}$ for Mo and $10 \mathrm{nM}$ for Se. For experiments with Fragilariopsis curta the final concentration of Zn was increased to $500 \mathrm{nM}$, as initial experiments showed that this species had a high requirement for this element. The iron concentrations in each 11 bottle of media were adjusted with an iron-EDTA stock that had been freshly prepared from $0.1 \mathrm{M} \mathrm{FeCl}_{3}$ (in $0.01 \mathrm{M} \mathrm{HCl}$ ) and 0.1 M EDTA stock. Total dissolved iron concentrations were 500, 300, 100, 50, 25, 12.5 and $6.25 \mathrm{nM}$. Metal speciation in the media at the start of the experiment was calculated by the method of Gerringa et al. (2000).

All cultures were grown at $1^{\circ} \mathrm{C}$ under $70 \mu \mathrm{mol}$ photons $\mathrm{m}^{-2} \mathrm{~s}^{-1}$ light supplied by cool white fluorescent lights (Philips). Prior to the start of the experiment each species was acclimated to each concentration of iron; this involved maintaining cultures in exponential growth at each level of iron for at least 3 transfers (4 to 9 wk depending on iron concentration and species) at which point growth rates and $F_{\mathrm{v}} / F_{\mathrm{m}}$ (quantum yield of fluorescence) values were stable.

The growth rate data were fitted to a Monod growth function:

$$
\mu=\frac{\mu_{\max } \times\left[\mathrm{Fe}^{\prime}\right]}{K_{\mathrm{m}}+\left[\mathrm{Fe}^{\prime}\right]}
$$

where $\mu$ is the growth rate, $\mu_{\max }$ is the maximum growth rate, $\mathrm{Fe}^{\prime}$ is the inorganic iron concentration and $K_{\mathrm{m}}$ is the half-saturation growth constant.

The acclimated cultures were inoculated in triplicate into $500 \mathrm{ml}$ jars containing $300 \mathrm{ml}$ of media. The amount of inoculum used was that required to achieve a dark-adapted fluorescence value $\left(F_{\mathrm{o}}\right)$ of 100 at photomultiplier (PM) gain setting 14 to 16 on a water PAM fluorometer (Walz) zeroed with a filtered seawater blank. This level of fluorescence was determined to be the lowest that could be reliably measured by the instrument and corresponded to around 10000 to 20000 cells ml $\mathrm{ml}^{-1}$ for Fragilariopsis cylindrus and 4000 to 8000 cells $\mathrm{ml}^{-1}$ for $F$. curta. The 2-fold range in cell concentration for each species resulted from higher fluorescence per cell for the iron-stressed treatments. Samples $(3 \mathrm{ml})$ were withdrawn from each flask at regular intervals using trace-metal-clean and sterile techniques, and rapid light curves (RLC) were run under software control (WinControl, Walz) after $10 \mathrm{~s}$ of quasi-dark adaptation (Ralph \& Gademann 2005). These were used to calculate $\mathrm{rETR}_{\max }$ (maximum relative electron transfer rate), $\alpha$ (photosynthetic efficiency), $\beta$ (photoinhibition index), and $E_{\mathrm{k}}$ (lightadaptation parameter). The same sample was then dark adapted for 30 min before assessing $F_{\mathrm{v}} / F_{\mathrm{m}}$. Dark-adapted $F_{\text {o }}$ values were used to calculate growth rates of each treatment by linear regression of $\ln F$ versus time.

A weak measuring light $\left(0.15 \mu \mathrm{mol}\right.$ photons $\left.\mathrm{m}^{-2} \mathrm{~s}^{-1}\right)$ was used to measure the fluorescence yield, while a saturating pulse (>3000 $\mu \mathrm{mol}$ photons $\mathrm{m}^{-2} \mathrm{~s}^{-1}$ for $0.8 \mathrm{~s}$ ) was used to determine the maximum steady-state fluorescence. Chlorophyll fluorescence was detected at wavelengths $>710 \mathrm{~nm}$. Blue-light emitting diodes (LED) provided actinic light used in the RLCs at levels of $0,37,85,125,194,289,413$ and 577 . Relative electron transport rate was derived according to the equation (Schreiber 2004):

$$
\mathrm{rETR}=F_{\mathrm{v}} / F_{\mathrm{m}} \times \mathrm{PAR}
$$

RLCs are described using several characteristic parameters, such as $E_{\mathrm{k}_{1}} \alpha, \beta$ and $\mathrm{rETR}_{\max }$ (McMinn et al. 2003). To determine these parameters, the RLCs were fitted to an exponential curve following Platt et al. (1980). This process described the photosynthetic re- 
sponse as a single continuous function of light, covering both the initial linear response, as well as the photoinhibited region at elevated light. Data were exported from WinControl (Walz) into SPSS (v.12.0.1). Empirical data were mathematically fitted to a doubleexponential decay function (Platt et al. 1980), using a Marquardt-Levenberg regression algorithm, such that:

$$
P=P_{\mathrm{m}}\left(1-\mathrm{e}^{-\left(\alpha E_{\mathrm{d}} / P_{\mathrm{s}}\right)}\right) \mathrm{e}^{-\left(\beta E_{\mathrm{d}} / P_{\mathrm{s}}\right)}
$$

As photoinhibition was not seen (i.e. $\beta=0$ ), the function becomes a standard rectangular hyperbola, with an asymptotic maximum rETR value and can be simplified to:

$$
P=P_{\mathrm{m}}\left(1-\mathrm{e}^{-\left(\alpha E_{\mathrm{d}} / P_{\mathrm{s}}\right)}\right)
$$

where $P_{\mathrm{s}}$ is a scaling factor defined as the maximum potential rETR in the absence of photoinhibitory processes, $P_{\mathrm{m}}$ is the photosynthetic capacity at saturating light, $\alpha$ is the initial slope of the RLC before the onset of saturation, $E_{\mathrm{d}}$ is the downwelling irradiance (400 to $700 \mathrm{~nm})$, and $\beta$ characterizes the slope of the RLC beyond the onset of photoinhibition (Henley 1993). $E_{\mathrm{k}}$ is the photoadaptive index or minimum saturating irradiance and is calculated as:

$$
E_{\mathrm{k}}=\mathrm{rETR}_{\max } / \alpha
$$

The proportions of energy dissipated as heat (nonphotochemical quenching, NPQ) were calculated according to the following equation (Schreiber 2004):

$$
\mathrm{NPQ}=\left(F_{\mathrm{m}}-F_{\mathrm{m}}{ }^{\prime}\right) / F_{\mathrm{m}}{ }^{\prime}
$$

where $F_{\mathrm{m}}$ is the maximum fluorescence in the dark and $F_{\mathrm{m}}{ }^{\prime}$ is the maximum fluorescence in the light.

When cultures had grown to a fluorescence value between 3000 and 4000 relative units with the instrument set at the PM gain chosen at the beginning of the experiment, aliquots were taken for cell counts and duplicate chlorophyll determination. The remainder of the culture was concentrated on polycarbonate membranes (Osmonics) with pore sizes of $2 \mu \mathrm{m}$ (Fragilariopsis cylindrus) or $5 \mu \mathrm{m}$ ( $F$. curta) under vacuum of $<5 \mathrm{mmHg}$, and then washed from the membrane into a micro-centrifuge tube. Cell material was pelleted by centrifugation at $1000 \times g$, and the pellets were frozen at $-80^{\circ} \mathrm{C}$ until analysis of the proteins by Western blotting (Pankowski \& McMinn 2008).

An additional experiment was conducted to determine the rate of recovery of Fragilariopsis cylindrus from Fe stress over a period of $24 \mathrm{~h}$. F. cylindrus cultures grown at a Fe concentration of $6.25 \mathrm{nM}$ were transferred to media with a concentration of $500 \mathrm{~nm}$. The photosynthetic parameters $F_{\mathrm{v}} / F_{\mathrm{m}}, \alpha, \mathrm{rETR}_{\max }$ and chlorophyll a cell ${ }^{-1}$ were measured at 3, 612 and $24 \mathrm{~h}$. Flavodoxin and ferredoxin concentrations were measured at 6, 12 and $24 \mathrm{~h}$.

\section{RESULTS}

\section{Growth}

There was a clear effect of iron concentration on growth rate for both Fragilariopsis cylindrus and $F$. curta (Fig. 1). Maximum growth rates $\left(\mu_{\max }\right)$ were $0.57 \mathrm{~d}^{-1}$ for $F$. cylindrus and $0.28 \mathrm{~d}^{-1}$ for $F$. curta, whilst $K_{\mathrm{m}}$ for growth was $0.51 \times 10^{-12}$ and $1.3 \times 10^{-12}$ $M$ for $F$. cylindrus and $F$. curta, respectively, where the concentrations represent the sum of all inorganic iron species $\left[\mathrm{Fe}^{\prime}\right]=\left[\mathrm{Fe}^{3+}\right]+\left[\mathrm{Fe}(\mathrm{OH})^{2+}\right]+\left[\mathrm{Fe}(\mathrm{OH})_{2}{ }^{+}\right]$. At its lowest growth rate of $0.34 \mathrm{~d}^{-1}$ in media containing $0.69 \mathrm{pM} \mathrm{Fe}$ (6.25 $\left.\mathrm{nM} \mathrm{Fe} \mathrm{Fetal}_{\text {tot }}\right), F$. cylindrus grew at $60 \%$ of its calculated $\mu_{\text {max }}$. Under similar conditions F. curta grew at a rate of $0.14 \mathrm{~d}^{-1}$, which was $50 \%$ of its maximum rate.

For Fragilariopsis cylindrus, mean growth rates at the 4 highest concentrations of iron ranged from 0.530 to $0.586 \mathrm{~d}^{-1}$ and therefore represent growth at close to maximum rates. For this species, the level of iron required to achieve a decrease in growth of $10 \%$ (a reduction seen as biologically significant and representative of the onset of iron-limited growth) was 2.78 pM Fe' (25 nM Fe total $)$.

For Fragilariopsis curta, cultures grown with 55.5, 33.3 and 11.1 pM Fe' $\left(500,300\right.$ and 100 nM Fe $\left.e_{\text {total }}\right)$ grew at rates that were within $10 \% \mu_{\text {max }}$. For this species, the growth rate decreased below $90 \% \mu_{\max }$ when supplied with 5.55 pM Fe' (50 nM Fe $e_{\text {total }}$ ) or less.

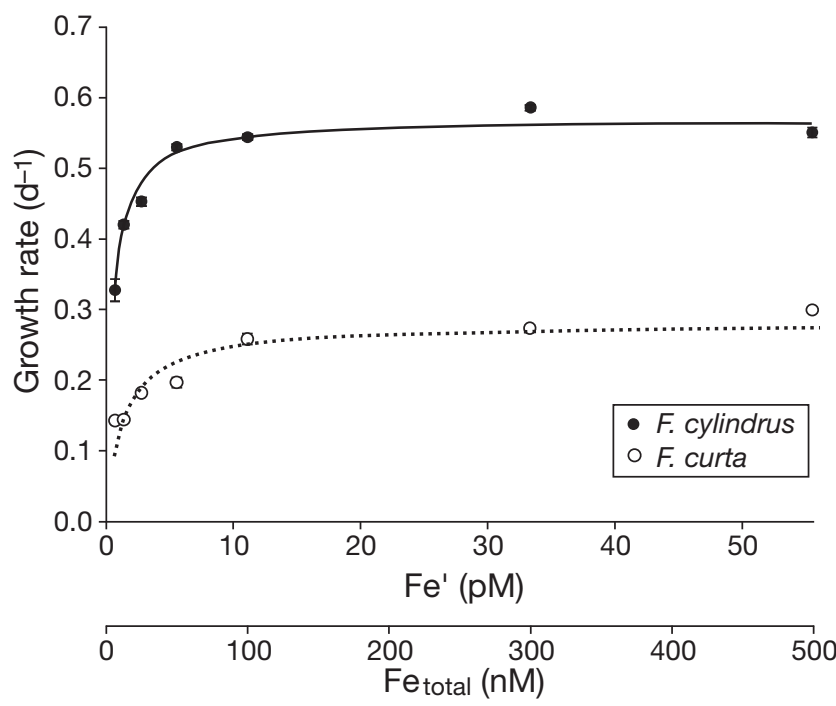

Fig. 1. Fragilariopsis cylindrus and F. curta. Growth rates in relation to inorganic $\left(\mathrm{Fe}^{\prime}\right)$ and total $\left(\mathrm{Fe}_{\text {total }}\right)$ iron concentrations. Error bars indicate SE ( $=3$ ) and, when not visible, are smaller than symbols. Lines represent modelled Monod growth curves 


\section{PAM fluorometry}

For both Fragilariopsis cylindrus and F. curta, $F_{\mathrm{v}} / F_{\mathrm{m}}$ was highest and lowest for the cultures grown with the highest and lowest concentrations of iron, respectively. The relationship between $F_{\mathrm{v}} / F_{\mathrm{m}}$ and iron concentration was similar to that observed for growth rate (Fig. 2). Both species were close to reaching their maximum $F_{\mathrm{v}} / F_{\mathrm{m}}(F$. cylindrus $=0.65, F$. curta $=0.56)$ with the 3 highest iron concentrations, i.e. when the iron concentration was $>100 \mathrm{nM}$. More distinct reductions in $F_{\mathrm{v}} / F_{\mathrm{m}}$ occurred for organisms growing at $\mathrm{Fe}^{\prime}$ concentrations below $5.55 \mathrm{pM}$ (50 nM Fe total $)$.

For Fragilariopsis cylindrus the maximum observed $F_{\mathrm{v}} / F_{\mathrm{m}}$ was 0.64 , and the most iron-limited cultures of this species had an $F_{\mathrm{v}} / F_{\mathrm{m}}$ of 0.34 . This level of reduction is indicative of moderate to severe nutrient stress.

Maximum observed $F_{\mathrm{v}} / F_{\mathrm{m}}$ for Fragilariopsis curta was somewhat lower (0.56), but still within the range expected for nutrient-sufficient phytoplankton. In this species, $F_{\mathrm{v}} / F_{\mathrm{m}}$ was less responsive to iron stress than growth rate. For cultures grown at the lowest concentration of iron of $0.69 \mathrm{pM} \mathrm{Fe}$ (6.25 nM Fe $\left.\mathrm{petal}_{\text {tol }}\right), F_{\mathrm{v}} / F_{\mathrm{m}}$ was reduced by $25 \%$ of that observed for the $500 \mathrm{nM}$ grown culture, whilst growth rate was suppressed by $50 \%$.

Representative RLCs for Fragilariopsis cylindrus and F. curta grown at each concentration of iron are shown in Figs. $3 \& 4$. The corresponding cardinal points, $\mathrm{rETR}_{\max }, \alpha$ and $E_{\mathrm{k}}$ derived from curves taken of triplicate cultures of each species at each treatment level are presented in Table 1. Several of the RLCs for F. cylindrus had not reached a maximum; thus, the given $\mathrm{rETR}_{\max }$ is likely to be an underestimate. This does not affect the subsequent interpretation of the data,

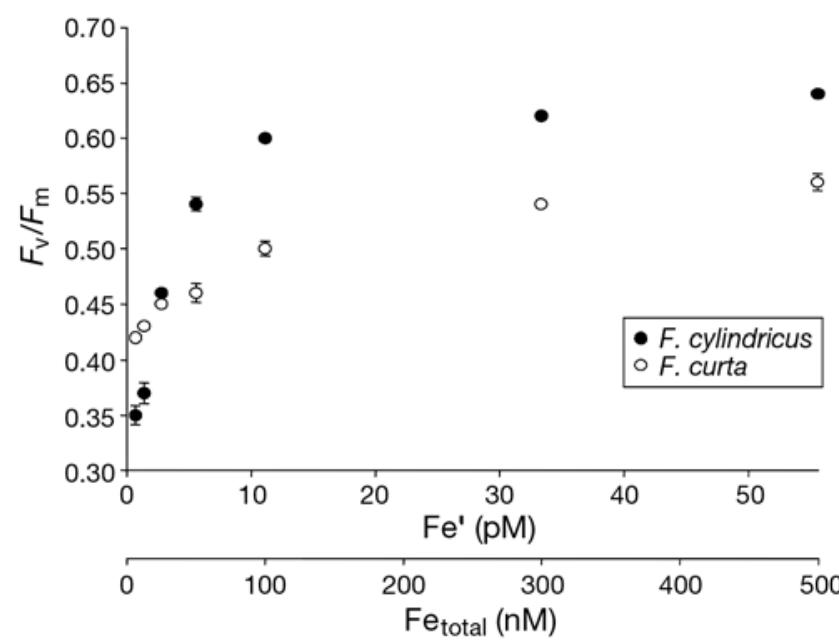

Fig. 2. Fragilariopsis cylindrus and $F$. curta. $F_{\mathrm{v}} / F_{\mathrm{m}}$ as a function of inorganic iron ( $\left.\mathrm{Fe}^{\prime}\right)$ and total iron $\left(\mathrm{Fe}_{\text {total }}\right)$. Error bars indicate $\mathrm{SE}(\mathrm{n}=3)$ and, when not visible, are smaller than symbols

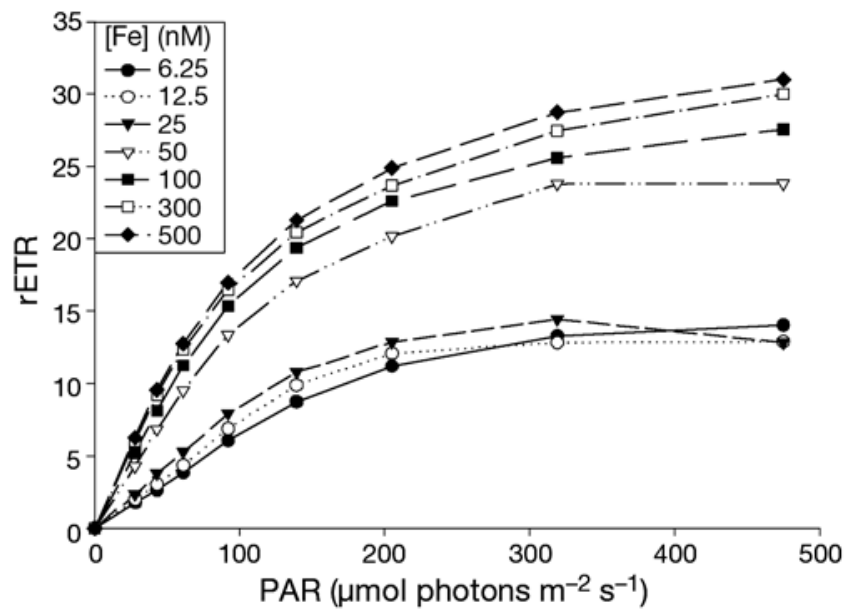

Fig. 3. Fragilariopsis cylindrus. Representative rapid light curves for $F$. cylindrus grown at 7 concentrations of iron. rETR: relative electron transfer rate; PAR: photosynthetically active radiation

but emphasises the different responses of the 2 species to iron.

For both species there was a clear reduction in both $\mathrm{rETR}_{\max }$ and $\alpha$ with decreasing iron availability. For Fragilariopsis cylindrus grown with the lowest concentration of iron, $\mathrm{rETR}_{\max }$ was half that of the iron-replete value, while $\alpha$ was reduced by $65 \%$. For F. curta the reductions in these parameters were slightly lower (30\% for $\mathrm{rETR}_{\max }$ and $50 \%$ for $\alpha$ ). Changes in $E_{\mathrm{k}}$ were not as well defined as the other 2 parameters, but did show the general trend of higher values at the lowest iron concentrations. This trend is more evident from plots of relative $\mathrm{rETR}_{\max }$ versus relative $\alpha$ for each species (Fig. 5). For both species the linear trend had a slope greater than unity. This demonstrates that for

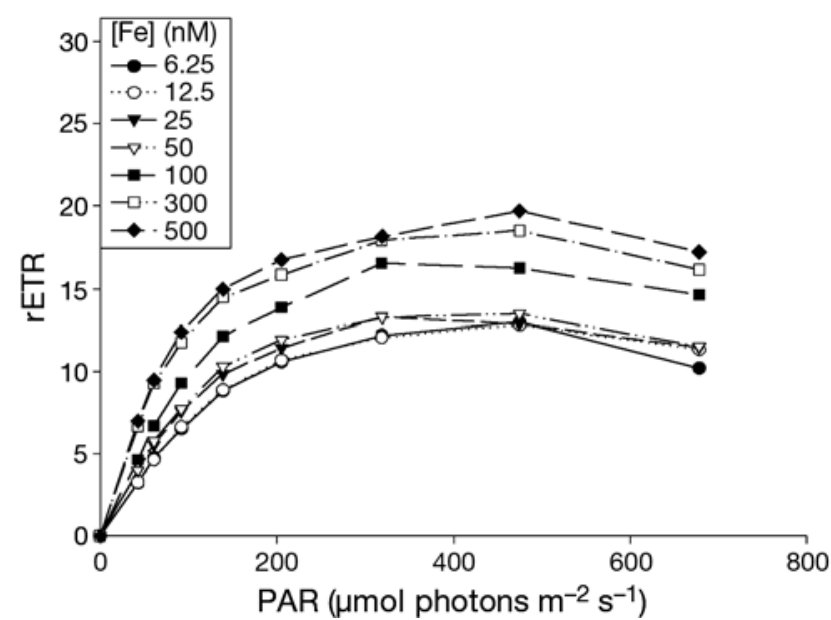

Fig. 4. Fragilariopsis curta. Representative rapid light curves for $F$. curta grown at 7 concentrations of iron. rETR: relative electron transfer rate; PAR: photosynthetically active radiation 
Table 1. Fragilariopsis cylindrus and F. curta. Rapid light curve parameters for F. cylindrus and F. curta grown at 7 concentrations of iron. Values represent means $( \pm \mathrm{SE}, \mathrm{n}=3)$. $\mathrm{rETR}_{\text {max }}$ : maximum relative electron transport rate; $E_{\mathrm{k}}$ : photosynthetic efficiency

\begin{tabular}{|c|c|c|c|c|c|c|}
\hline \multirow{2}{*}{$\mathrm{Fe}(\mathrm{nM})$} & \multicolumn{2}{|c|}{$\mathrm{rETR}_{\max }$} & \multicolumn{2}{|c|}{$-\alpha$} & \multicolumn{2}{|c|}{$E_{\mathrm{k}}$} \\
\hline & F. cylindrus & F. curta & F. cylindrus & F. curta & F. cylindrus & F. curta \\
\hline 6.25 & $37.6 \pm 2.1$ & $32.1 \pm 1.0$ & $0.212 \pm 0.017$ & $0.236 \pm 0.014$ & $181 \pm 22$ & $139 \pm 12$ \\
\hline 12.5 & $33.3 \pm 1.9$ & $31.7 \pm 0.2$ & $0.252 \pm 0.010$ & $0.240 \pm 0.010$ & $133 \pm 2$ & $133 \pm 6$ \\
\hline 25 & $39.5 \pm 6.4$ & $32.4 \pm 0.0$ & $0.283 \pm 0.021$ & $0.288 \pm 0.014$ & $145 \pm 35$ & $112 \pm 6$ \\
\hline 50 & $60.0 \pm 3.1$ & $33.3 \pm 1.7$ & $0.479 \pm 0.021$ & $0.298 \pm 0.010$ & $126 \pm 12$ & $112 \pm 9$ \\
\hline 100 & $66.4 \pm 1.9$ & $40.7 \pm 1.2$ & $0.552 \pm 0.005$ & $0.343 \pm 0.014$ & $120 \pm 4$ & $119 \pm 5$ \\
\hline 300 & $71.2 \pm 1.4$ & $44.0 \pm 2.1$ & $0.590 \pm 0.010$ & $0.481 \pm 0.029$ & $120 \pm 1$ & $93 \pm 10$ \\
\hline 500 & $74.0 \pm 3.1$ & $45.7 \pm 0.0$ & $0.619 \pm 0.005$ & $0.495 \pm 0.017$ & $120 \pm 6$ & $93 \pm 3$ \\
\hline
\end{tabular}

both species declines in $\alpha$ were greater than reductions in $\mathrm{rETR}_{\max }$, resulting in $E_{\mathrm{k}}$ shifting to higher values for the low-level iron cultures. This effect was more pronounced for $F$. curta (slope $=1.28$ ) than for $F$. cylindrus (slope $=1.13$ ).

The ability of cultures to develop NPQ as light levels increased during RLCs is shown in Fig. 6 for Fragilariopsis cylindrus and Fig. 7 for F. curta. Iron-replete F. cylindrus showed the ability to develop a moderate level of NPQ. For these cultures the NPQ coefficient approached 0.4 for the highest light level experienced during the RLCs. There was a clear effect of iron on the ability of $F$. cylindrus to develop NPQ. Iron stress led to a decreased ability to dissipate excess light energy by non-photochemical mechanisms. F. cylindrus grown with the lowest concentration of iron developed approximately $35 \%$ of the NPQ of iron-sufficient cells at the highest light level. F. curta developed less NPQ than F. cylindrus despite higher light levels (final irradiance of light curve was $678 \mathrm{vs} 475 \mu \mathrm{mol}$ photons $\mathrm{m}^{2} \mathrm{~s}^{-1}$ for F. curta vs F. cylindrus, respectively), and the ability to develop NPQ did not vary with the level of iron.

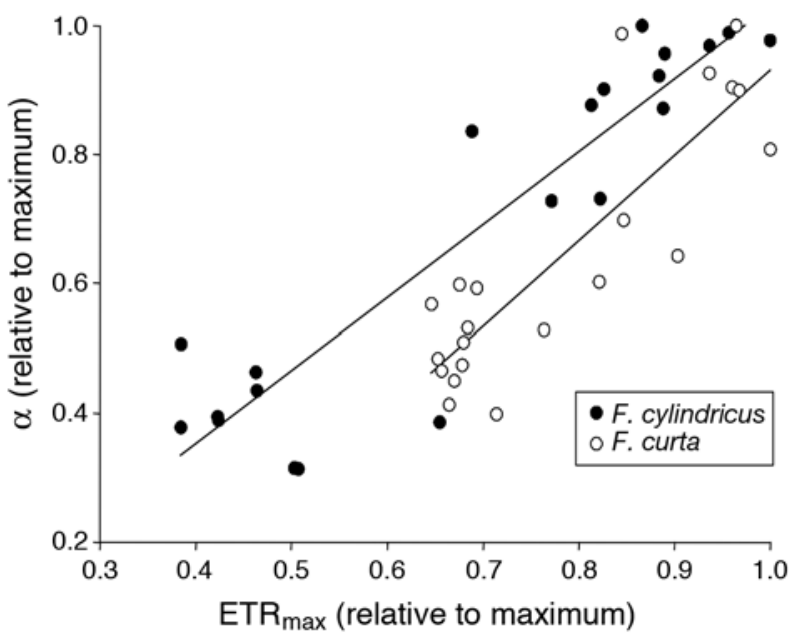

Fig. 5. Fragilariopsis cylindrus and F. curta. Plot of $\mathrm{rETR}_{\max }$ versus relative $\alpha$ for cultures of $F$. cylindrus and $F$. curta grown at 7 concentrations of iron

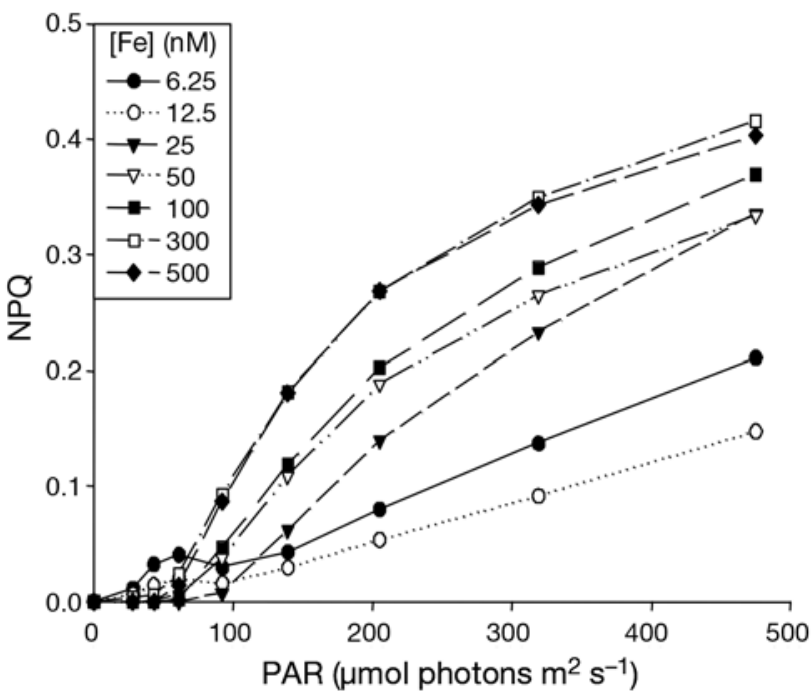

Fig. 6. Fragilariopsis cylindrus. Non-photochemical quenching (NPQ) developed during rapid light curves by F. cylindrus cultures grown at 7 concentrations of iron

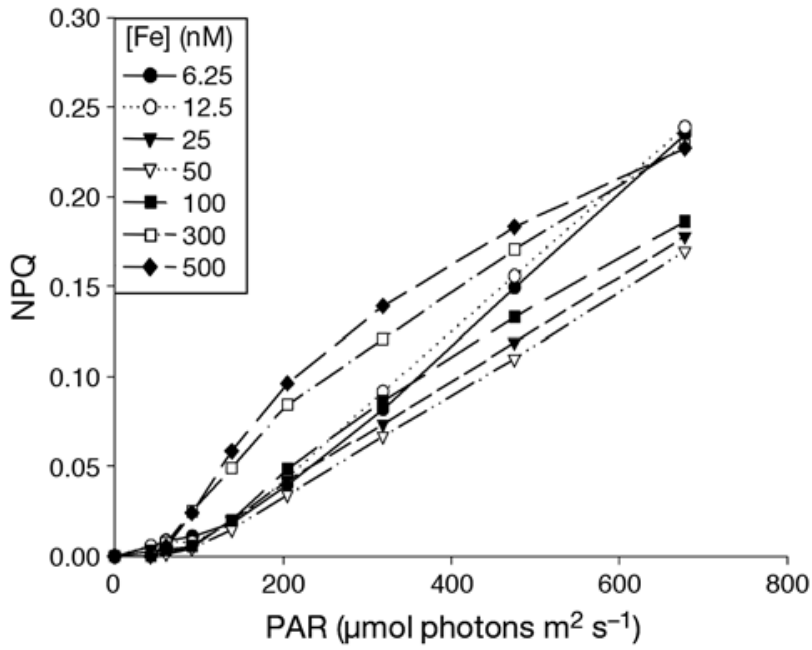

Fig. 7. Fragilariopsis curta. Non-photochemical quenching (NPQ) developed during rapid light curves by F. curta cultures grown at 7 concentrations of iron 
Table 2. Fragilariopsis cylindrus and F. curta. Chlorophyll and protein content of F. cylindrus and F. curta grown at 7 concentrations of iron

\begin{tabular}{|lcccc|}
\hline \multirow{2}{*}{ Fe } & \multicolumn{2}{c|}{ Chlorophyll (fg cell ${ }^{-1}$ ) } & \multicolumn{2}{c|}{ Protein (fg cell ${ }^{-1}$ ) } \\
$(\mathrm{nM})$ & F. cylindrus & F. curta & F. cylindrus & F. curta \\
\hline 6.25 & $9.5 \pm 1.1$ & $1.06 \pm .06$ & $0.85 \pm 0.04$ & $54.1 \pm 4.2$ \\
12.5 & $9.6 \pm 0.6$ & $1.01 \pm 0.06$ & $0.86 \pm 0.05$ & $49.2 \pm 8.5$ \\
25 & $11.6 \pm 2.8$ & $1.15 \pm 0.01$ & $0.64 \pm 0.03$ & $55.1 \pm 4.6$ \\
50 & $13.7 \pm 0.9$ & $1.09 \pm 0.09$ & $0.82 \pm 0.07$ & $53.5 \pm 5.0$ \\
100 & $16.1 \pm 1.0$ & $1.54 \pm 0.06$ & $0.73 \pm 0.08$ & $67.5 \pm 7.8$ \\
300 & $18.6 \pm 1.2$ & $1.33 \pm 0.09$ & $1.00 \pm 0.10$ & $56.5 \pm 7.1$ \\
500 & $17.5 \pm 0.9$ & $1.76 \pm 0.06$ & $0.93 \pm 0.11$ & $73.0 \pm 4.4$ \\
\hline
\end{tabular}

\section{Chlorophyll and protein}

Results for chlorophyll and total protein are expressed on a per cell basis in Table 2. Chlorophyll content of cells was highest for organisms grown at the highest iron concentrations for both species. For both species, decreasing iron in the media led to progressively lower cellular chlorophyll concentrations. The relative stepwise decrease in chlorophyll content at each concentration of iron was similar for the 2 species. The lowest per cell concentrations were observed in the cultures grown with the least iron and were 55 to $60 \%$ of the maximum values for both species. For both species, cellular protein content did not show any consistent response to iron availability.

\section{Ferredoxin and flavodoxin}

An example of a Western immunoblot for ferredoxin and flavodoxin conducted on total proteins extracted from Fragilariopsis cylindrus is shown in Fig. 8a. Iron availability had a clear effect on the expression of these proteins in this organism. Cultures grown with 55.5 pM Fe' (500 nM Fe total ) produced predominantly ferredoxin, with a small amount of flavodoxin staining detectable but well below the lowest standard loaded on the gel and therefore not quantifiable. Ferredoxin was replaced by flavodoxin for cultures grown with less iron, but the response was not a simple switch from one protein to another. Cultures grown with both 33.3 pM Fe' (300 nM Fe $e_{\text {total }}$ ) and 11.1 pM Fe' (100 nM $\left.\mathrm{Fe}_{\text {total }}\right)$ expressed both proteins, with a greater amount of ferredoxin compared to flavodoxin produced by the organism at the higher iron concentration. For cultures supplied with $5.55 \mathrm{pM} \mathrm{Fe}$ (50 nM Fe total ) or less, only flavodoxin was expressed. The amounts of each protein produced under each treatment level were quantified against a standard curve of known amounts of the pure proteins from Cylindrotheca closterium (Fig. 9a). When both proteins are expressed as moles of catalyst, flavodoxin appeared to replace some but not all of the ferredoxin expression, leading to a decline in the total concentration of catalyst with increasing iron stress. When ferredoxin expression was completely suppressed (50 $\left.\mathrm{nM} \mathrm{Fe}_{\text {total }}\right)$, flavodoxin levels were maximal and did not increase for cultures that were suffering from a greater level of iron stress.
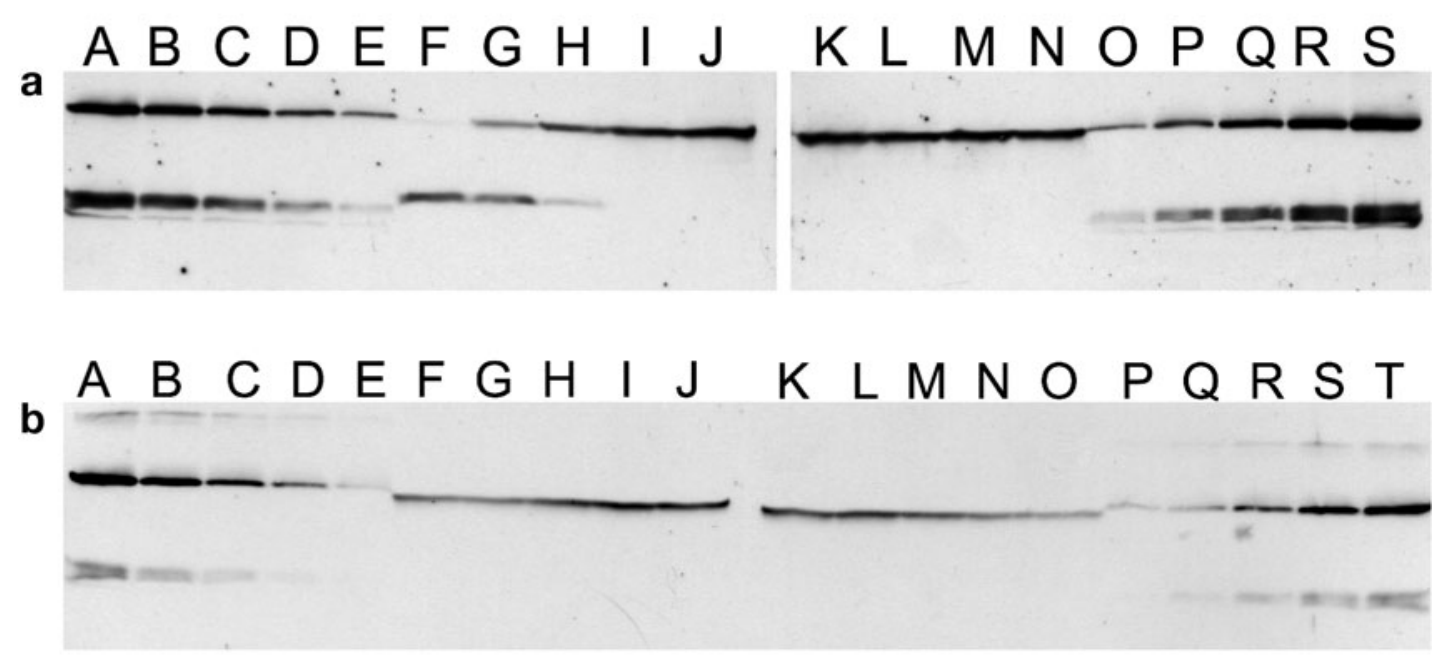

Fig. 8. Fragilariopsis cylindrus and F. curta. Western immunoblots characterising expression of ferredoxin and flavodoxin in cultures of: (a) F. cylindrus. Lanes A to E and O to S: purified standards of flavodoxin (upper) and ferredoxin (lower) in the range of 5 to $50 \mathrm{ng}$. Lanes $\mathrm{F}$ to $\mathrm{N}$ : proteins from F. cylindrus cultures grown with the following amounts of iron; $500 \mathrm{nM}$ (Lane F), $300 \mathrm{nM}$ (Lane G), $100 \mathrm{nM}$ (Lane H), $50 \mathrm{nM}$ (Lane I), $25 \mathrm{nM}$ (Lane J), $6.25 \mathrm{nM}$ (Lane K), $12.5 \mathrm{nM}$ (Lane L), $25 \mathrm{nM}$ (Lane M) and $50 \mathrm{nM}$ (Lane N). (b) F. curta. Lanes A to E and P to T: purified standards of flavodoxin (upper) and ferredoxin (lower) in the range of 5 to 50 ng. Lanes F to O: proteins from F. curta cultures grown with the following amounts of iron; $500 \mathrm{nM}$ (Lane F), $300 \mathrm{nM}$ (Lane G), $100 \mathrm{nM}$ (Lane H), $50 \mathrm{nM}$ (Lane I), 25 nM (Lane J), $6.25 \mathrm{nM}$ (Lane K), $12.5 \mathrm{nM}$ (Lane L), $25 \mathrm{nM}$ (Lane M), $50 \mathrm{nM}$ (Lane N) and $100 \mathrm{nM}$ (Lane O) 


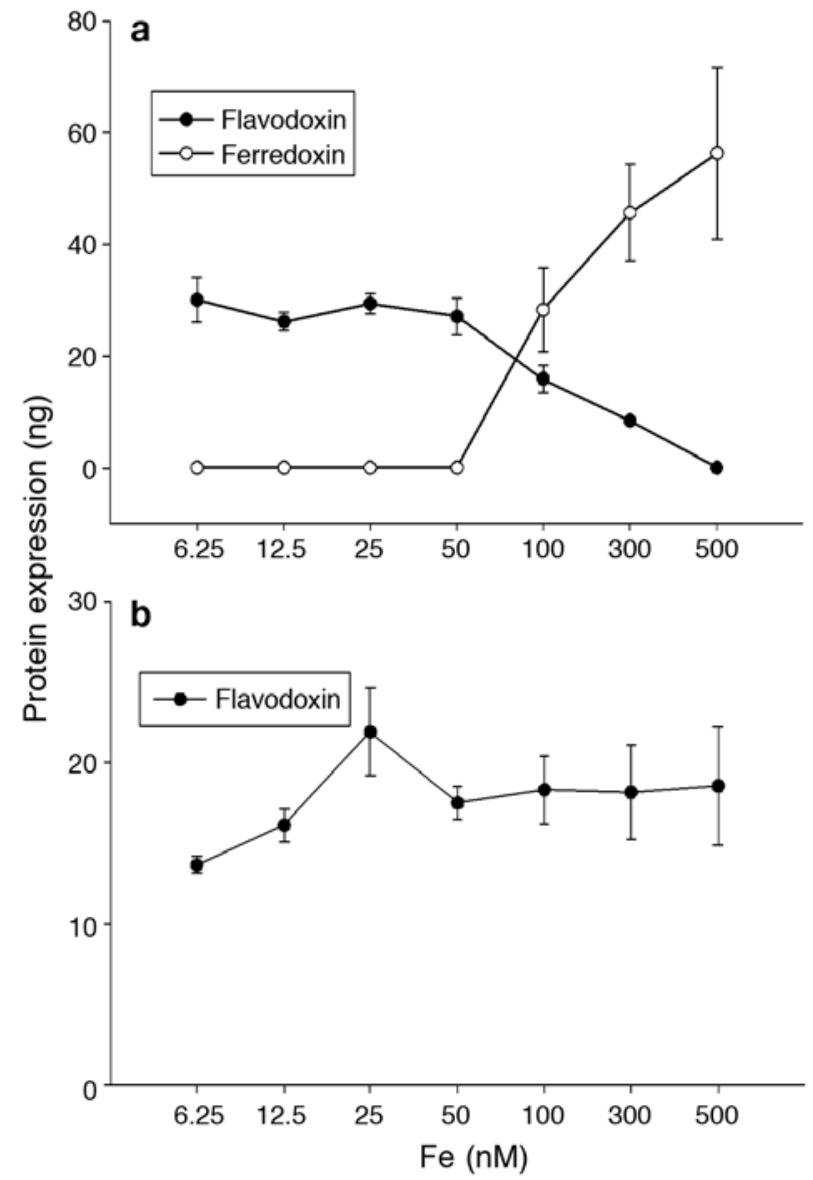

Fig. 9. Fragilariopsis cylindrus and F. curta. Flavodoxin and ferredoxin expression in cultures of (a) $F$. cylindrus and (b) $F$. curta grown in media with different iron concentrations

The equivalent blots and graph for Fragilariopsis curta (Figs. 8b \& 9b) suggest that the ability to produce ferredoxin is absent in this organism. The data presented for replicate cultures at each treatment level (Fig. 9b) show relatively constant levels of flavodoxin across all treatments.

\section{Recovery of Fragilariopsis cylindrus from iron limitation}

PAM fluorometry, extracted chlorophyll analysis and Western blotting were used to monitor the recovery of F. cylindrus cultures from iron stress. There were considerable differences in the rates of change of the various parameters measured. Changes in the photosynthetic parameters $F_{\mathrm{v}} / F_{\mathrm{m}}$ and $\mathrm{rETR}_{\max }$ are shown in Fig. 10a,b.

Small changes in $F_{\mathrm{v}} / F_{\mathrm{m}}$ and $\alpha$ were evident within $3 \mathrm{~h}$ of adding iron to iron-stressed cultures. The increase in these 2 parameters was linear over the $24 \mathrm{~h}$
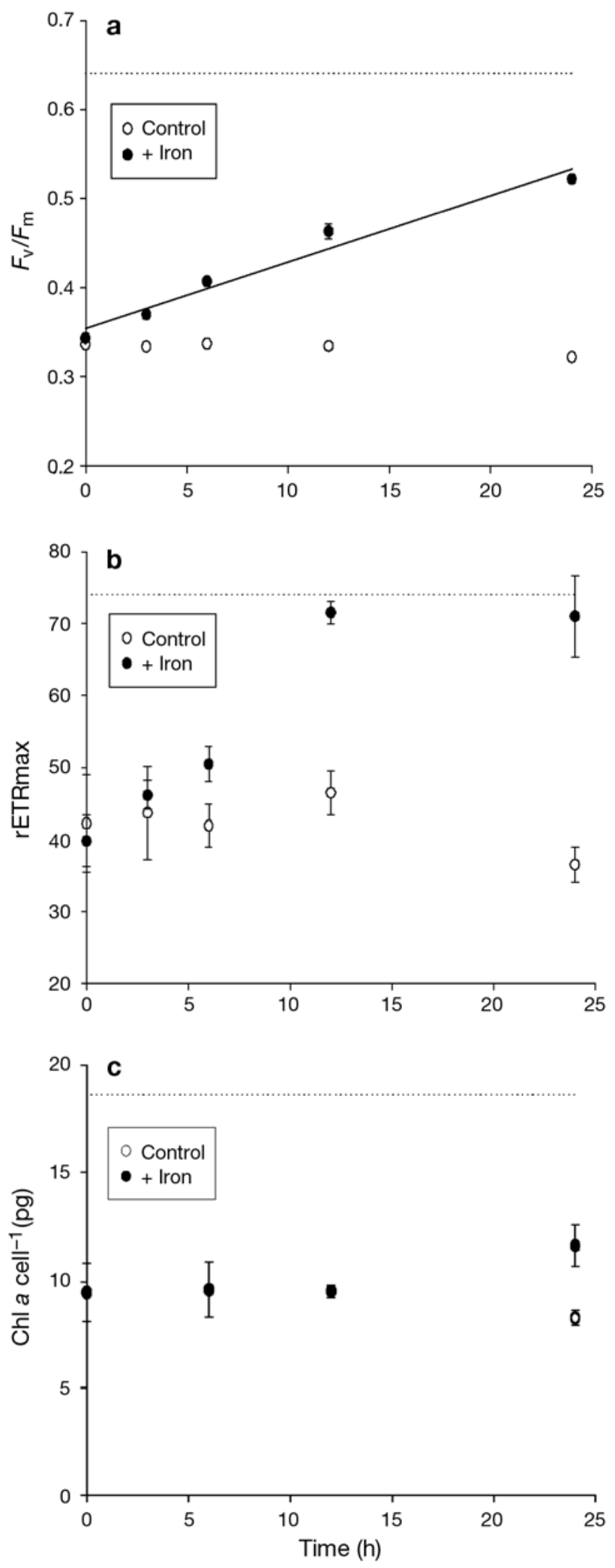

Fig. 10. Fragilariopsis cylindrus. Recovery from iron stress. Changes in (a) $F_{\mathrm{v}} / F_{\mathrm{m}}$ (b) $\mathrm{rETR}_{\max }$ and (c) chlorophyll a per cell. Dotted line: values of $500 \mathrm{nM}$ culture. Symbols overlap for first 3 values in (c) 
period. Twenty-four hours after addition of iron, $F_{\mathrm{v}} / F_{\mathrm{m}}$ had recovered to approximately $80 \%$ of iron-replete levels and $\alpha$ to within $70 \%$. If recovery of these 2 parameters were to continue at the observed rates, $\alpha$ and $F_{\mathrm{v}} / F_{\mathrm{m}}$ would have reached iron-replete values after approximately $40 \mathrm{~h}$.

Recovery of $\mathrm{rETR}_{\max }$ occurred with different kinetics. Recovery of this parameter in the first $6 \mathrm{~h}$ occurred at a similar rate to increases in $F_{\mathrm{v}} / F_{\mathrm{m}}$. During the second $6 \mathrm{~h}$ period, the recovery rate of this parameter accelerated and reached iron-replete levels within $12 \mathrm{~h}$ of iron addition and remained at this level for the final sampling time period.

Chlorophyll per cell (Fig. 10c) and ferredoxin expression (Fig. 11) were much slower to show signs of change. There was no change evident in cellular chlorophyll levels until the $24 \mathrm{~h}$ time point, when chlorophyll levels had increased by $20 \%$ compared to control levels. Recovery to iron-replete levels would involve a doubling of pre-recovery levels of chlorophyll per cell.

After $12 \mathrm{~h}$ a faint band for ferredoxin was observed, but this was well below the lowest standard loaded on the gel and therefore below quantitation (Fig. 11). After $24 \mathrm{~h}$, expression of ferredoxin was more sustained and had increased to a similar level (in terms of moles catalyst) as that of flavodoxin (Fig. 11). At the same time there was no significant decline in flavodoxin expression. Ferredoxin and flavodoxin levels at this time point were similar to the $100 \mathrm{nM}$ grown cultures, although by comparison $F_{\mathrm{v}} / F_{\mathrm{m}}$ and $\alpha$ were close to those values of the $50 \mathrm{nM}$ culture, chlorophyll per cell was at levels comparable to those of the $25 \mathrm{nM}$ culture, whilst $\mathrm{rETR}_{\max }$ was equivalent to that of the $500 \mathrm{nM}$ culture. Hence, although synthesis of ferredoxin began slowly, it recovered more fully than $F_{\mathrm{v}} / F_{\mathrm{m}}$, $\alpha$, or cellular chlorophyll concentrations, but not as rapidly as $\mathrm{rETR}_{\max }$ (Fig. 12).

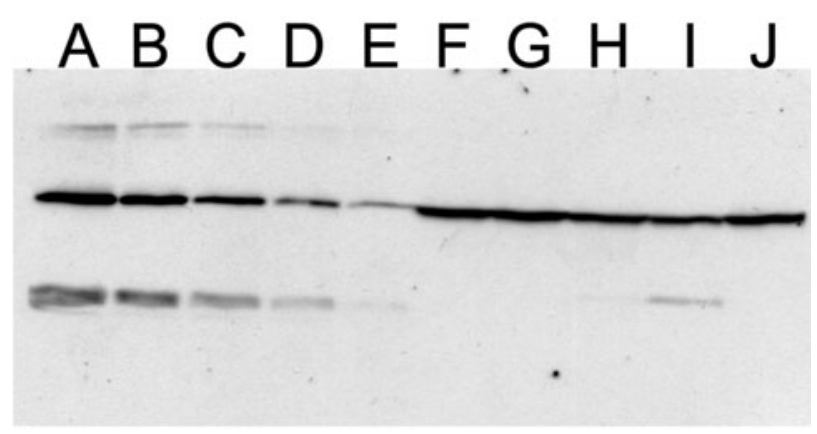

Fig. 11. Fragilariopsis cylindrus. Flavodoxin and ferredoxin expression in $F$. cylindrus during recovery from iron stress. Lanes A to E: protein standards in the range of 50 to $5 \mathrm{ng}$ (flavodoxin upper, ferredoxin lower); $\mathrm{T}=0$ (Lane F), $+\mathrm{Fe} 6 \mathrm{~h}$ (Lane G), +Fe $12 \mathrm{~h}$ (Lane H), +Fe $24 \mathrm{~h}$ (Lane I) and control $24 \mathrm{~h}$ (Lane J)

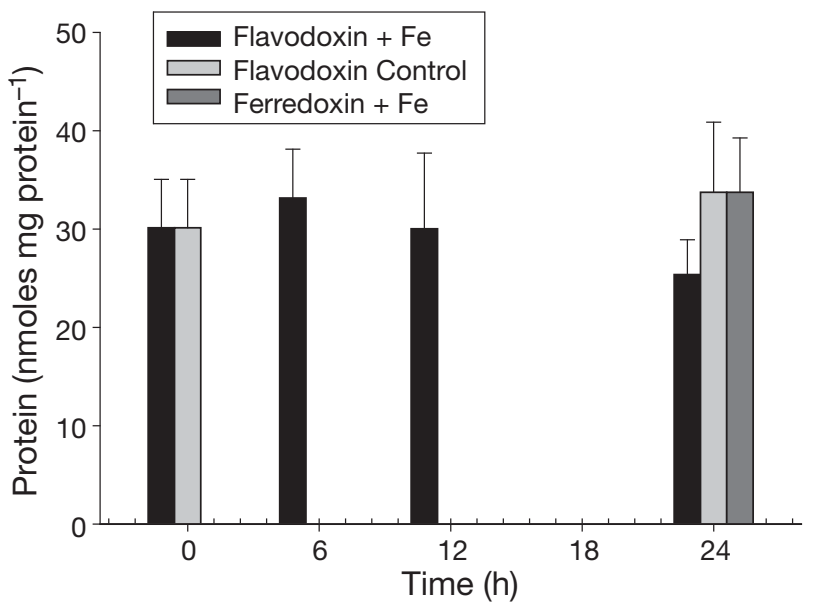

Fig. 12. Fragilariopsis cylindrus. Flavodoxin and ferredoxin during recovery of $F$. cylindrus from iron limitiation. Values are expressed as moles of protein per $40 \mu \mathrm{g}$ of cellular protein (standard amount loaded per gel). Error bars represent SE $(\mathrm{n}=3)$

\section{DISCUSSION}

\section{Growth}

The maximum growth rate of Fragilariopsis cylindrus $\left(0.57 \mathrm{~d}^{-1}\right)$ in trace-metal-buffered media was similar to that observed by Fiala \& Oriol (1990) under equivalent light and temperature conditions in $f$ medium, and identical to the rate observed in $f / 2$ medium for this strain (Pankowski \& McMinn 2009). Growth of $F$. curta in this medium was $75 \%$ of that observed for this strain in $f / 2$ medium under similar light intensity (Pankowski \& McMinn 2009).

The growth rate data fitted to a Monod function yielded similar $K_{\mathrm{m}}$ values for both species. With respect to total inorganic iron [Fe'], these were $0.51 \times 10^{-12} \mathrm{M}$ for F. cylindrus and $1.3 \times 10^{-12} \mathrm{M}$ for F. curta. For both species, reductions in the growth rate to below $90 \%$ of the maximum occurred at around 2.8 to $5.6 \mathrm{pM} \mathrm{Fe}$ (25 to $50 \mathrm{nM} \mathrm{Fe}$ total), and, at the lowest concentration of iron in the experiment, both species grew at around half their maximum rates.

Comparison of these $K_{\mathrm{m}}$ values to those reported in the literature for other phytoplankton is complicated by differences in the methods used to estimate inorganic iron and uncertainties as to which chemical species of iron are available for uptake by phytoplankton in various media. For example, $K_{\mathrm{m}}$ for $\mathrm{Fe}^{\prime}$ of the Antarctic diatom Chaetocerous brevis grown in media buffered with EDTA was $2 \times 10^{-12} \mathrm{M}$ (Timmermans et al. 2001a). The same species and strain grown in lowiron-concentration seawater with added desferrioxamine had a $K_{\mathrm{m}}$ for [Fe'] 2 orders of magnitude lower, but a $K_{\mathrm{m}}$ for dissolved iron (the sum of $\mathrm{Fe}^{\prime}$ and the concen- 
Table 3. Half-saturation growth constant $K_{\mathrm{m}}$ [Fe'] and cell volume for temperate and polar phytoplankton of both neritic and oceanic habitats

\begin{tabular}{|c|c|c|}
\hline Species & $K_{\mathrm{m}}\left[\mathrm{Fe}^{\prime}\right]$ & Cell volume $\left(\mu \mathrm{m}^{3}\right)$ \\
\hline Thalassiosira oceanica $^{\mathrm{a}}$ & $0.18 \times 10^{-12}$ & 90 \\
\hline T. pseudonana ${ }^{\mathrm{a}}$ & $3.6 \times 10^{-12}$ & 30 \\
\hline T. weissflogii ${ }^{\mathrm{a}}$ & $3.0 \times 10^{-12}$ & 840 \\
\hline Chaetoceros brevis ${ }^{\mathrm{b}}$ & $2.0 \times 10^{-12}$ & 50 \\
\hline Fragilariopsis curta $^{\mathrm{c}}$ & $1.3 \times 10^{-12}$ & 750 \\
\hline F. cylindrus ${ }^{\mathrm{c}}$ & $0.51 \times 10^{-12}$ & 90 \\
\hline \multicolumn{3}{|c|}{$\begin{array}{l}\text { a Sunda \& Huntsman (1995) with [Fe'] re-calculated } \\
\text { b'Timmermans et al. (2001a) } \\
\text { 'P Present study }\end{array}$} \\
\hline
\end{tabular}

tration of iron bound to the natural organic ligands in seawater) of $0.59 \times 10^{-12} \mathrm{M}$ (Timmermans et al. $2001 \mathrm{~b}$ ). Shaked et al. (2005) recently presented evidence for an iron uptake model for diatoms, whereby both inorganic iron and organically bound iron are available for uptake, but all species must undergo reduction to a +2 oxidation state at the cell surface prior to uptake. In this model, uptake in EDTA-buffered media largely occurs through reduction of inorganic iron species at the cell surface. For the same reason, direct comparisons with iron concentrations in natural seawater and sea ice, in which most of the iron is bound in organic molecules, is also difficult. Iron concentrations in coastal areas are extremely variable and can exceed 500 nM (Cannizzaro et al. 2000). Values from offshore areas of the Southern Ocean, by comparison, are consistently low and usually <0.2 nM (Martin et al. 1990). Values $<1 \mathrm{nM}$ are generally thought to be Fe-limiting (Sedwick et al. 2000). Iron concentrations between 0.36 and 53 nM have been reported from sea ice (Edwards \& Sedwick 2001). These sea ice iron concentrations are higher than those of the surrounding ocean, as nutrients are concentrated by brine rejection during ice growth. Comparisons of inorganic iron (Fe', $\mathrm{pM})$, give more consistent results between studies than comparisons of total iron $\left(\mathrm{Fe}_{\text {total }}, \mathrm{nM}\right)$ (Timmermans et al. 2001a).

Growth-rate data for other diatoms grown in EDTAbuffered media were used to calculate $K_{\mathrm{m}}$ values based on $\left[\mathrm{Fe}^{\prime}\right]$ estimated using the metal speciation calculations reported in the present study and those reported by Timmermans et al. (2001a). The values fall within a range of approximately 1 order of magnitude (Table 3). Those reported in the present study for Fragilariopsis cylindrus and F. curta are in the middle of the range of presented values. The calculations used ignore the photo-dissociation of iron EDTA complexes that increase steady-state inorganic iron concentrations (Gerringa et al. 2000). Hence, actual values of $K_{\mathrm{m}}$ [Fe'] are likely to be higher than the values reported here. However, values reported for Chaetoceros brevis are directly comparable to those of F. cylindrus and F. curta, because the same light and temperature conditions were used in both experiments. Although light intensity and temperature were higher during the experiments conducted on the temperate species (500 $\mu \mathrm{mol}$ photons $\mathrm{m}^{-2} \mathrm{~s}^{-1}, 20^{\circ} \mathrm{C}$ ) compared to during the experiments on polar organisms, the increase in steady-state [Fe'] (and hence $K_{\mathrm{m}}\left[\mathrm{Fe}^{\prime}\right]$ ) due to iron EDTA photo-dissociation are likely to be of similar magnitude.

At low temperatures, rates of thermal dissociation and association of iron EDTA complexes are lower, but photo-dissociation rates remain largely unchanged (Sunda \& Huntsman 2003). Based on the observed changes in rates of thermal reactions compared to photolysis at $10^{\circ} \mathrm{C}$ compared to at $20^{\circ} \mathrm{C}$ (Sunda \& Huntsman 2003), the increase in [Fe'] caused by $70 \mu \mathrm{mol}$ photons $\mathrm{m}^{-2} \mathrm{~s}^{-1}$ light at $1^{\circ} \mathrm{C}$ would be similar to the increase due to $500 \mu \mathrm{mol}$ photons $\mathrm{m}^{-2} \mathrm{~s}^{-1}$ light at $20^{\circ} \mathrm{C}$, approximately a factor of 3.5 . Hence, the values are comparable and suggest that, within the narrow size range of these diatoms, there is no clear effect of size or habitat (neritic/oceanic or polar/temperate) on a diatom's $K_{\mathrm{m}}\left[\mathrm{Fe}^{\prime}\right]$ for growth.

$K_{\mathrm{m}}\left[\mathrm{Fe}^{\prime}\right]$ growth represents the concentration of iron required to achieve a growth rate half of maximal and therefore provides an indication of a diatom's overall ability to maintain growth under low-level iron conditions. With falling iron concentrations, a diatom with a high $K_{\mathrm{m}}$ [Fe'] will experience physiological impairment sooner than a diatom with low $K_{\mathrm{m}}$ [Fe'] growth. The values do not represent the quota or iron use efficiency of the diatom, which is a measure of the amount of iron a diatom requires to generate a unit amount of biomass.

Sunda \& Huntsman (1997) suggest that the options available to oceanic algal species to grow under low iron concentrations are: (1) to become smaller, which increases the surface area:volume ratio; (2) to reduce intracellular iron quotas; or (3) to grow more slowly. The reduced maximum growth rate of the larger species, Fragilariopsis curta, clearly contributes to its ability to maintain growth at similar iron concentrations to its smaller competitor F. cylindrus.

\section{Effects of iron on photosynthesis and pigments}

As well as the observed halving of the growth rate, there were significant changes to photosynthetic parameters and cellular chlorophyll levels. The magnitudes of these changes were similar for both organisms. One of the most consistent and obvious effects of iron on Chaetoceros muelleri (Davey \& Geider 2001) and the 
Antarctic flagellate limitation was a reduction in $\alpha$ values.

Decreases in $\alpha$ have also been observed in iron-limited cultures of Pyramimonas sp. (van Leeuwe \& de Baar 2000). In other studies, $\alpha$ values were not affected by iron limitation in cultures of the Antarctic diatom Chaetoceros brevis (van Oijen et al. 2004) or the neritic diatom Phaeodactylum tricornutum (Greene et al. 1991). In all but one of the above-mentioned studies $\alpha$ values were calculated from ${ }^{14} \mathrm{C}$ uptake and normalised to a per chlorophyll basis. Alpha values obtained by PAM RLCs reflect the probability of light energy captured by an antenna unit being used for PSII photochemistry (quantum yield for PSII charge separation) under weak actinic illumination. Hence, $\alpha$ reflects the effective quantum yield of PSII under low light conditions. Chlorophyll-specific $\alpha$ values from traditional photosynthesis versus irradiance curves are irradiance-specific rates of photosynthetic oxygen evolution or carbon assimilation and are equivalent to the product of the quantum yield of photosynthesis $(\Phi$, which is proportional to the quantum yield for PSII charge separation) and the chlorophyll-specific light absorption coefficient $\left(a^{*}\right)$. In the study on P. tricornutum, iron limitation led to a decrease in $\Phi$, but an increase in $a^{*}$ (due to reductions in pigment content and a decrease in the package effect), with the net result that $\alpha$ remained unchanged (Greene et al. 1991). The clear decreases in $\alpha$ observed in iron-limited Pyramimonas sp. and $C$. muelleri suggest that in these studies decreases in $\Phi$ were much greater than increases in $a^{*}$. These results, as well as those observed here for Fragilariopsis cylindrus and F. curta, suggest that a consistent effect of iron limitation is to decrease the quantum yield of photosynthesis, most likely due to changes that occur to PSII that reduce the efficiency of charge separation. In the marine alga Dunaliella tertiolecta, alterations to PSII resulting from iron limitation included an uncoupling of pigment antenna units from the PSII reaction centres, which coincided with lower expression of a number of PSII-associated proteins (Vassiliev et al. 1995).

Rapid light curve $\alpha$ values and $F_{\mathrm{v}} / F_{\mathrm{m}}$ measure the quantum yield of PSII under light-limited photosynthesis and dark-adapted states, respectively. A comparison of the 2 can provide information about the functioning of the photosynthetic apparatus at sub-saturating irradiances. Alpha values were consistently lower than $F_{\mathrm{v}} / F_{\mathrm{m}}$ for all cultures, but the difference between $\alpha$ and $F_{\mathrm{v}} / F_{\mathrm{m}}$ was not the same for iron-limited and iron-replete cultures. For the most iron-limited treatments for both organisms $\alpha$ was $60 \%$ of $F_{\mathrm{v}} / F_{\mathrm{m}}$, whilst, for cultures grown with the highest concentration of iron, $\alpha$ was $>90 \%$ $F_{\mathrm{v}} / F_{\mathrm{m}}$. This suggests that, for the most iron-limited cultures, weak illumination caused a relatively large percentage of reaction centres to close. Conversely, the majority of reaction centres remained open for the iron-replete cultures under the weak illumination experienced during the early steps of the RLC.

Plots of $F$ and $F_{\mathrm{m}}$ ' against irradiance for Fragilariopsis cylindrus and F. curta grown under iron-replete and iron-limited conditions showed similar features (Fig. 13). For iron-replete cultures (Fig. 13b), increasing light intensity during the RLC caused a gradual increase in the minimal steady-state fluorescence value $F$ to approximately $150 \%$ of the quasi-darkadapted value. Furthermore, when irradiance exceeded environmental levels maximum fluorescence $F_{\mathrm{m}}{ }^{\prime}$ declined in a sigmoidal fashion. The $F_{\mathrm{m}}$ ' of iron-limited cultures (Fig. 13a) also declined with rising light levels; however, the overall decrease in $F_{\mathrm{m}}{ }^{\prime}$ was less and began at higher irradiance. Steady-state fluorescence $F$ of iron-limited cells showed a very different response to iron-replete cells, increasing only at the first level of actinic light and then remaining constant for all subsequent light levels.

Declines in $F_{\mathrm{m}}$ ' are characteristic of the induction of non-photochemical quenching mechanisms, which are usually associated with the build up of a proton gradient across the thylakoid membrane (energy-dependent quenching, qE) (Buchel \& Wilhelm 1993). The relaxation kinetics observed for this quenching, i.e. complete relaxation within 30 min of dark adaptation, is also consistent with the quenching being of the $\mathrm{qE}$ variety (Krause \& Weis 1991). Smaller declines in $F_{\mathrm{m}}$ ' of iron-limited cells indicate less development of nonphotochemical quenching, which is consistent for the observed lower NPQ coefficient for iron-limited Fragi-
Fig. 13. Fragilariopsis cylindrus. Changes in steadystate $(F)$ and maximum $\left(F_{\mathrm{m}}\right)$ fluorescence during rapid light curves for (a) ironlimited and (b) iron-replete cultures

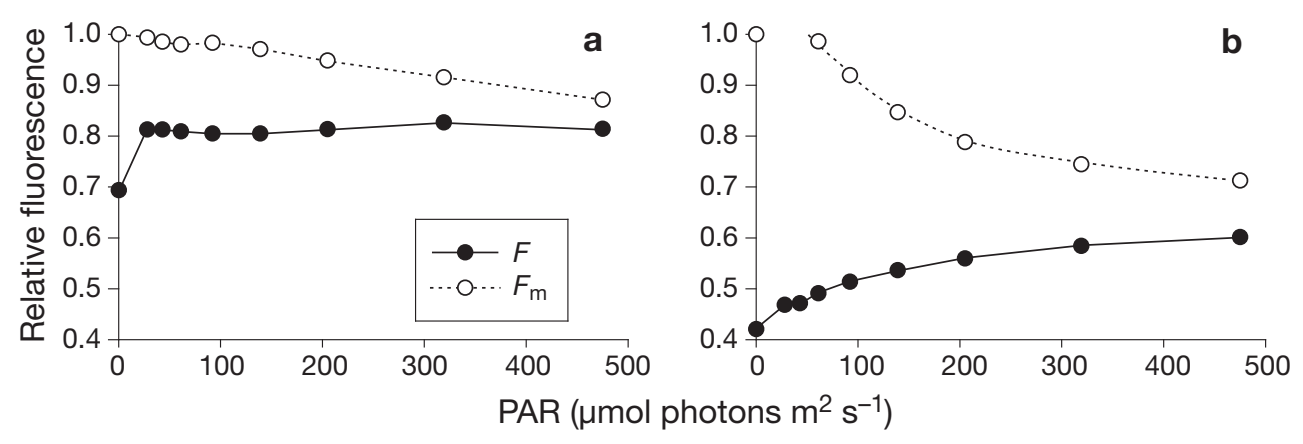


lariopsis cylindrus cultures compared to cultures of this organism grown under iron-replete conditions. That non-photochemical quenching began to develop at higher irradiance in iron-limited cells suggests that higher photon fluxes were required to build the transthylakoid proton gradient $(\Delta \mathrm{pH})$ in iron-limited cells.

Increases in steady-state fluorescence $F$ upon illumination are thought to reflect the oxidation state of the plastaquinone pool (PQ) and, as a consequence, the proportion of reduced primary accepter $Q_{\mathrm{A}}$ (Kolber \& Falkowski 1993). As more of the plastaquinone pool becomes reduced, less is available to reoxidize $Q_{\mathrm{A}}$, resulting in more reaction centres being closed to the transfer of absorbed photon energy. Ralph \& Gademann (2005) suggest that an increase in $F$ during a RLC reflects insufficient 'sink' capacity to remove the electrons generated at the PSII reaction centres. This is particularly evident in low-light-adapted organisms, which maximize light capture at low irradiance, but have limited ability to process high electron fluxes (Ralph \& Gademann 2005). Hence, iron-replete F. cylindrus and F. curta showed characteristics of adaptation to moderate light levels. F increased steadily with increasing irradiance suggestive of an imbalance between electron generation by PSII and usage of these reducing equivalents through carbon fixation.

In iron-limited cells the increase in $F$ at quite low irradiance and only at the onset of actinic illumination could similarly be due to an increase in the extent of reduction of the plastaquinone pool. However, as it occurred under very low light levels, with the effective quantum yield (and $F$ ) remaining relatively constant for the following 5 steps of the light curve, it more likely indicates a closure of a subset of the reaction centres under low light. Such closures could occur if a subset of reaction centres were of the $Q_{\mathrm{A}}$ non-reducing type (Krause \& Weis 1991). That $F$ remained constant with further increases in irradiance suggests that the capacity to utilise electrons was greater than the ability to generate them. This is consistent with the observation that iron-limited cells began to develop non-photochemical quenching at higher irradiance. Only when photon flux densities are relatively high can iron-limited cells generate enough $\Delta \mathrm{pH}$ to induce the build-up of non-photochemical quenching.

Iron-limited growth also resulted in suppression of $\mathrm{rETR}_{\max }$. Furthermore, declines in $\mathrm{rETR}_{\max }$ were not as great as the observed decreases in $\alpha$, causing $E_{\mathrm{k}}$ to shift to higher irradiance. This further demonstrates that iron limitation caused larger reductions to light capture and primary charge separation relative to electron processing capacity downstream from PSII. In iron-replete cultures, $E_{\mathrm{k}}$ was close to environmental light levels, indicating that the organisms were growing at close to light saturation with limited ability to photo- chemically utilise the increased photon fluxes when light levels exceed environmental levels. Iron-limited cultures, however, were growing at sub-saturating irradiance, where the capacity to process energy downstream of PSII is greater than the capacity to carry out light capture and primary charge separation.

The results presented here are consistent with ironinduced changes in photosynthesis being mainly due to effects on PSII. Various alterations to the photosynthetic electron transport chain have been postulated to cause a reduction in maximal quantum yield for PSII due to iron limitation. Vassiliev et al. (1995) reported that iron limitation causes a significant reduction in the abundance of Light Harvesting Complex II (LHCII) proteins, which coincided with PSII reaction centres becoming energetically isolated. Reduced transfer of excitation energy from closed PSII reaction centres to open centres was also observed, along with changes in the rate of electron transport through the photosynthetic electron transport chain. These latter changes were thought to be the result of decreased abundance of certain functional proteins on the acceptor side of PSII (e.g. cytb559), which resulted in less efficient reduction of the primary acceptor $Q_{\mathrm{A}}$. Evidence for alterations to the rate of electron transfer through PSI has also been observed as a result of a reduction in certain iron-containing proteins in this photosystem (Greene et al. 1992). Although alterations to PSI may have occurred in Fragilariopsis cylindrus and F. curta, they were masked by more substantial relative changes to PSII.

\section{Ferredoxin and flavodoxin expression in relation to iron supply, growth and physiology}

Phytoplankton faced with falling concentrations of an essential nutrient respond to the stress by initiating changes to cellular biochemistry, which represent an attempt to mitigate the effects of falling nutrient availability. These changes may include the induction of acquisition systems, for example, the up-regulation of membrane-bound metal transport ligands, replacement of one catalyst for another, as occurs with the replacement of ferredoxin and flavodoxin, and the progressive down-regulation of metabolic processes (La Roche et al. 1999). Alterations to cellular composition and biochemical processes in response to decreased nutrient availability can precede reductions in growth rate. For example, Morel et al. (1991) suggested that microalgae growing with replete amounts of a given trace metal express sub-maximal densities of membrane-bound transporters for that metal. When the availability of a trace metal falls to a critical level, where the organism's full quota cannot be met, the number of transport ligands increases. This allows the organism to 
maintain growth at near maximum rates. This physiological state, where the growth rate is near maximum, but compensatory mechanisms have been induced, is called metal stress (Morel et al. 1991). When ligand transport density reaches a maximum level and other mechanisms cannot compensate for the decreased metal availability, growth rates fall and the organism enters metal limitation. A useful definition of the onset of metal limitation is a growth rate $90 \%$ of maximum (Morel et al. 1991). Hence, changes in cellular biochemistry or physiology that result from reduced trace metal availability, but that are not accompanied by a reduction in growth rate, are evidence of metal stress.

Based on the above definitions for metal stress and metal limitation, the substitution of ferredoxin for flavodoxin in Fragilariopsis cylindrus begins as an early response to iron stress. For this organism the cultures grown with 300 and $100 \mathrm{nM}$ iron contained both ferredoxin and flavodoxin and showed photosynthetic parameters and cellular chlorophyll concentrations that were around $90 \%$ of the values observed for the $500 \mathrm{nM}$ (iron replete) cultures. Full replacement of ferredoxin for flavodoxin was observed in the $50 \mathrm{nM}$ cultures, which grew at rates which were still $>90 \%$ $\mu_{\max }$, i.e. the organisms were not growing under iron limitation. These cultures grown with $50 \mathrm{nM}$ iron showed only minor symptoms of iron stress, with photosynthetic parameters and per cell chlorophyll concentrations suppressed by around $20 \%$ compared to maximum.

Davey \& Geider (2001) observed that substantial increases in flavodoxin expression caused by iron stress had little effect on growth rates, light-saturated photosynthesis rates, variable fluorescence, or intersystem electron transport in cultures of the diatom Chaetocerous muelleri. These authors also observed that under the highest levels of iron stress, small increases in flavodoxin were accompanied by large changes in photosynthetic parameters. Fragilariopsis cylindrus grown at a pFe' of $2.8\left(25 \mathrm{nM} \mathrm{Fe} \mathrm{e}_{\text {total }}\right)$ or less grew at rates that were substantially limited by iron availability. For these treatments, each incremental reduction in iron caused a drop in growth rate and further reductions of $\alpha$ and $\mathrm{rETR}_{\max } F_{\mathrm{v}} / F_{\mathrm{m}}$ values, however, remained constant for these cultures. The different responses of these 2 species may reflect the different growing conditions; F. cylindrus had already acclimated to the low iron concentration, while C. muelleri was experiencing actively falling iron levels. Under such circumstances, rates of change to photosynthetic parameters through processes such as damage and degradation of photosynthetic units may be more rapid than protein synthesis rates. Hence, an acclimated state in which flavodoxin expression is truly related to iron supply may not have been reached. Erdner et al. (1999) similarly observed that flavodoxin was expressed in Thalassiosira weissflogii at growth rates of 80 to $90 \%$ maximum. These authors also examined ferredoxin expression in this organism and suggested that when growth rates were limited by iron the relative abundance of ferredoxin and flavodoxin (the ferredoxin index) had the potential to indicate the severity of iron stress. McKay et al. (1999) observed that the accumulation of flavodoxin coincided with impairment of photochemistry in Phaeodactylum tricornutum; however, the level of impairment observed was minor, corresponding to the small decrease observed for $F$. cylindrus grown at $100 \mathrm{nM} \mathrm{Fe} \mathrm{e}_{\text {total }}$ compared to $500 \mathrm{nM}$.

Fragilariopsis curta showed similar trends to F. cylindrus in terms of growth rate, $\alpha, \mathrm{rETR}_{\text {max }}$ and $F_{\mathrm{v}} / F_{\mathrm{m}}$. For this organism, significant limitation of growth by iron occurred in the 4 treatments supplied with <5.6 pM [Fe'] (50 nM Fe total $)$. Apart from a $30 \%$ decrease in $\alpha$ for the $100 \mathrm{nM}$ grown culture, the cultures supplied with the 3 highest concentrations of iron showed little other evidence of physiological impairment. Furthermore, ferredoxin was never detected in this species, and flavodoxin levels were constant across all treatments.

Constitutive expression of flavodoxin has previously been observed in Rhizosolenia sp., but the expression of ferredoxin was not examined in this organism (McKay et al. 2000). In Thalassiosira weissflogii a constitutive flavodoxin was also reported, but was a minor fraction of the combined ferredoxin + flavodoxin pool (Doucette et al. 1996), and was suppressed by very high iron concentrations (Erdner et al. 1999). The lack of detection of ferredoxin in Fragilariopsis curta could have conceivably resulted from a lack of antibody cross reactivity towards the protein from this organism. If ferredoxin was the dominant catalyst in F. curta, but was simply not detected in iron-replete cultures, an up-regulation of flavodoxin would be expected under iron stress. The observed constant concentration of this catalyst in F. curta, however, suggests that ferredoxin is either a minor component or completely absent from this organism.

It is possible that other environmental factors might also influence flavodoxin expression in sea ice diatoms. Fluda \& Hagemann (1995) noted the expression of flavodoxin in a cyanobacterium in response to either iron or salinity stress. Furthermore, Yousef et al. (2003) found that the gene responsible for the up-regulation of flavodoxin in cyanobacteria was induced by any oxidative stress. However, in sea ice, the algal communities that are on the under-surface of the ice are in contact with normal salinities and the lowest light levels. These communities have the greatest expression of flavodoxin (Pankowski \& McMinn 2008). Communities in brine channels near the surface are exposed to elevated salinities and the greatest PAR and UV irradi- 
ances, but have the greatest expression of ferredoxin (Pankowski \& McMinn 2008). These results strongly imply that, in this environment, severe iron stress is responsible for the flavodoxin expression.

\section{Recovery of Fragilariopsis cylindrus from iron limitation}

Iron concentrations in much of the Southern Ocean are low, mostly $<1 \mathrm{nM}$ (Coale et al. 2005, Ellwood et al. 2008). While iron concentration within sea ice has recently been found to be up to an order of magnitude higher than that of the underlying water column (Lannuzel et al. 2007), these elevated levels would still be likely to limit growth of many sea ice diatoms. Furthermore, most ice algal biomass is concentrated at the bottom of floes, i.e. in contact with the low Fe waters of the Southern Ocean, and would therefore experience Fe-limited growth conditions similar to phytoplankton. Our data showed that severe nutrient stress occurred in both species examined at the lowest experimental iron values $(6.25 \mathrm{nM})$; ambient under-ice Fe levels would have had an $\mathrm{Fe}$ concentration an order of magnitude lower again; brine channel concentrations would have had a concentration within the lower range of our experiments and thus would still have experienced severe in situ Fe limitation

To conduct analyses for ferredoxin and flavodoxin on algae extracted from sea ice, the organisms must be extracted from the ice matrix by melting. The melting process can be completed within approximately $12 \mathrm{~h}$. A key concern was that during this time unavoidable contamination of samples with iron may result in changes to in situ ferredoxin and flavodoxin expression. Therefore, experiments were conducted to observe the temporal changes in recovery from iron limitation in Fragilariopsis cylindrus.

Changes in $F_{\mathrm{v}} / F_{\mathrm{m}}, \alpha, \mathrm{rETR}_{\max }$, chlorophyll and ferredoxin/flavodoxin occurred with different kinetics following the addition of iron to iron-limited cultures. The parameter that recovered first was FETR $_{\max }$, which attained iron-replete levels within $12 \mathrm{~h}$ of iron addition. Both $F_{\mathrm{v}} / F_{\mathrm{m}}$ and $\alpha$ increased with similar linear kinetics, and recovered to 80 and $70 \%$ of iron-replete values over the course of the $24 \mathrm{~h}$ experiment. Changes in $\alpha$ were, therefore, primarily due to increases in primary charge separation and are most likely due to an increase in functional PSII centres as has been observed previously (Vassiliev et al. 1995). Although both $\alpha$ and $\mathrm{rETR}_{\max }$ increased substantially during $24 \mathrm{~h}$ of recovery, $E_{\mathrm{k}}$ remained at higher than iron-replete levels. Hence, despite a recovery in the maximum relative electron transport rate, higher photon flux densities were required to achieve this rate.
Despite significant relaxation of constraints on photochemistry in the $24 \mathrm{~h}$ period, changes to protein expression and cellular chlorophyll concentrations occurred more slowly. Cellular chlorophyll concentrations increased only marginally in the $24 \mathrm{~h}$ period and only at the final time point. There was evidence of ferredoxin induction after $12 \mathrm{~h}$, with a faint band discernable on Western blots. Significant expression of this protein was not observed until the $24 \mathrm{~h}$ time point. During this time flavodoxin levels did not change significantly.

In cultures of the temperate diatom Phaeodactylum tricornutum complete replacement of flavodoxin with ferredoxin occurred within $8 \mathrm{~h}$ of iron re-supply, and major reductions in flavodoxin were observed prior to the detection of significant amounts of ferredoxin, suggesting active degradation of this protein (McKay et al. 1999). In this organism complete replacement of flavodoxin for ferredoxin was accompanied by an approximate doubling of $F_{\mathrm{v}} / F_{\mathrm{m}}$ (from 0.25 to 0.45 ).

The relative rates of recovery of $F_{\mathrm{v}} / F_{\mathrm{m}}$ and protein expression are similar in both species, but the slower absolute rates of Fragilariopsis cylindrus compared to those of Phaeodactylum tricornutum are consistent with the temperature dependence of biochemical processes.

Recovery of $F_{\mathrm{v}} / F_{\mathrm{m}}$ in both of these culture experiments are rapid compared to rates observed during open ocean iron enrichment in the Southern Ocean (Boyd et al. 2000) and Equatorial Pacific (Coale et al. 1996). During the experiment in the polar ocean a doubling of $F_{\mathrm{v}} / F_{\mathrm{m}}$ occurred in $4 \mathrm{~d}$, while a similar degree of recovery was observed in $24 \mathrm{~h}$ during the temperate ocean experiment. Slower recovery rates during field conditions compared to laboratory trials suggest that the more ideal light and iron regimes of laboratory studies accelerate the recovery process. During extraction of algae from ice cores, conditions for recovery are far from ideal. Contamination by iron is likely to only marginally increase iron supply. Furthermore, light can be excluded from the samples, and changes in salinity that occur during melting are known to physiologically stress these organisms (Ryan et al. 2004), which would likely further impair the process. Hence, changes in ferredoxin and flavodoxin levels during melting are unlikely.

\section{Ferredoxin and flavodoxin as markers for iron nutritional status}

In Fragilariopsis curta flavodoxin expression was found to be constitutive. The constant level of expression of this protein in this organism under conditions ranging from iron-replete growth to severe 
iron-limitation clearly precludes the use of this protein as a marker for iron nutritional status in this species. Widespread constitutive expression of flavodoxin by other sea ice-associated diatoms from both the Arctic and Antarctic (Pankowski \& McMinn 2009) would be expected to be under similar regulatory control to that of F. curta. Hence, neither flavodoxin abundance nor flavodoxin presence can be used to signify iron nutritional status in sea ice communities. In light of these results, it is interesting to re-assess the observed persistence of flavodoxin expression during the first Southern Ocean iron enrichment experiment (SOIREE) (Boyd et al. 2000). In this experiment $F_{\mathrm{v}} / F_{\mathrm{m}}$ attained values close to 0.5 , but flavodoxin expression persisted. This was thought to be due to incomplete alleviation of iron stress. The bloom that formed was dominated by F. kerguelensis. Based on the observed constitutive expression of flavodoxin in other closely related large oceanic Fragilariopsis species from both the Arctic and Antarctic (Pankowski \& McMinn 2009), it is likely that the observed persistence of flavodoxin was due to constitutive expression of flavodoxin in F. kerguelensis and other diatoms that bloomed in response to iron enrichment.

That flavodoxin is expressed as an early response to iron limitation in Fragilariopsis cylindrus and that its expression is maximal under conditions where neither growth was reduced nor photosynthesis significantly impaired means that neither the presence of this protein nor the ferredoxin index can be used to signify a level of stress that would have significant environmental consequences.

Although not all polar diatoms are capable of expressing ferredoxin, the ability to express this protein is retained in many Antarctic diatoms (Pankowski \& McMinn 2009). Fragilariopsis cylindrus, which retains this ability, has an almost ubiquitous distribution in this environment (Lizotte 2001). Some species capable of expressing ferredoxin would be present in most sea ice communities. The likely presence of ferredoxin-producing microalgae in most sea ice communities, coupled with the fact that this protein is present in F. cylindrus only when growth rates are maximal, suggests that the presence of this protein is likely to serve as an indicator of iron sufficiency in Antarctic sea ice. Finally, that the induction of ferredoxin in iron-limited F. cylindrus is slower than the time taken to process sea ice samples indicates that analyses conducted for these proteins will accurately reflect protein expression in situ.

Acknowledgements. We acknowledge financial support from an ARC Discovery Grant and logistical support from the Australian Antarctic Science Program. A.P. received support from an Australian postgraduate award.

\section{LITERATURE CITED}

Arrigo KR (2003) Primary production in sea ice. In: Thomas DN, Dieckmann G (eds) Sea ice: an introduction to its physics, chemistry, biology and geology. Blackwell Science, Oxford, p 143-183

Boyd PW (2002) Environmental factors controlling phytoplankton processes in the Southern Ocean. J Phycol 38: 844-861

Boyd PW, Watson AJ, Law CS, Abraham ER and others (2000) A mesoscale phytoplankton bloom in the polar Southern Ocean stimulated by iron fertilization. Nature 407:695-702

Boyd PW, Jickells T, Law CS, Blain S and others (2007) Mesoscale iron enrichment experiments 1993-2005: synthesis and future directions. Science 315:612-617

Brand LE (1991) Minimum iron requirements of marine phytoplankton and the implications for the biogeochemical control of new production. Limnol Oceanogr 36:1756-1771

Brierley AS, Thomas DN (2002) Ecology of Southern Ocean pack ice. Adv Mar Biol 43:171-277

Buchel C, Wilhelm C (1993) In-vivo analysis of slow chlorophyll fluorescence induction kinetics in algae-progress, problems and perspectives. Photochem Photobiol 58: $137-148$

Cannizzaro V, Bowie AR, Sax A, Achterberg EP, Worsfold PJ (2000) Determination of cobalt and iron in estuarine and coastal waters using flow injection with chemiluminescence detection. Analyst (Lond) 125:51-57

Coale KH, Johnson KS, Fitzwater SE, Gordon RM and others (1996) A massive phytoplankton bloom induced by an ecosystem-scale iron fertilization experiment in the equatorial Pacific Ocean. Nature 383:495-501

Coale KH, Gordon RM, Wang XJ (2005) The distribution and behavior of dissolved and particulate iron and zinc in the Ross Sea and Antarctic Circumpolar Current along 170 degrees W. Deep-Sea Res I 52:295-318

- Davey M, Geider RJ (2001) Impact of iron limitation on the photosynthetic apparatus of the diatom Chaetoceros muelleri (Bacillariophyceae). J Phycol 37:987-1000

Edwards R, Sedwick P (2001) Iron in East Antarctic snow: implications for atmospheric iron deposition and algal production in Antarctic waters. Geophys Res Lett 28: 3907-3910

Ellwood MJ, Boyd PW, Sutton P (2008) Winter-time dissolved iron and nutrient distributions in the SubAntarctic Zone from 40-52S: 155-160E. Geophys Res Lett 35:L11604, doi: 10.1029/2008GL033699

> Erdner DL, Price NM, Doucette GJ, Peleato ML, Anderson DM (1999) Characterization of ferredoxin and flavodoxin as markers of iron limitation in marine phytoplankton. Mar Ecol Prog Ser 184:43-53

> Fiala M, Oriol L (1990) Light-temperature interactions on the growth of Antarctic diatoms. Polar Biol 10:629-636

Fulda S, Hagemann M (1995) Salt treatment induces accumulation of flavodoxin in the cyanobacterium Synechocystis sp. pcc-6803. J Plant Physiol 146:520-526

> Gerringa LJA, de Baar HJW, Timmermans KR (2000) A comparison of iron limitation of phytoplankton in natural oceanic waters and laboratory media conditioned with EDTA. Mar Chem 68:335-346

Greene RM, Geider RJ, Falkowski PG (1991) Effect of iron limitation on photosynthesis in a marine diatom. Limnol Oceanogr 36:1772-1782

> Greene RM, Geider RJ, Kolber Z, Falkowski PG (1992) Ironinduced changes in light harvesting and photochemical energy-conversion processes in eukaryotic marine-algae. Plant Physiol 100:565-575 
Henley WJ (1993) Measurement and intepretation of photosynthesis - light response curves in algae in the context of photinhibition and diel changes. J Phycol 29:729-739

Kolber Z, Falkowski PG (1993) Use of active fluorescence to estimate phytoplankton photosynthesis in-situ. Limnol Oceanogr 38:1646-1665

Krause GH, Weis E (1991) Chlorophyll fluorescence and photosynthesis - the basics. Annu Rev Plant Physiol Plant Mol Biol 42:313-349

La Roche J, Geider RJ, Graziano LM, Murray H, Lewis K (1993) Induction of specific proteins in eukaryotic algae grown under iron-deficient, phosphorus-deficient, or nitrogen-deficient conditions. J Phycol 29:767-777

> La Roche J, Murray H, Orellana M, Newton J (1995) Flavodoxin expression as an indicator of iron limitation in marine diatoms. J Phycol 31:520-530

La Roche J, McKay RML, Boyd P (1999) Immunological and molecular probes to detect phytoplankton responses to environmental stress in nature. Hydrobiologia 401:177-198

Lannuzel D, Schoemann V, de Jong J, Tison JL, Chou L (2007) Distribution and biogeochemical behavior of iron in the East Antarctic sea ice. Mar Chem 106:18-32

Lizotte MP (2001) The contributions of sea ice algae to Antarctic marine primary production. Am Zool 41:57-73

Martin JH, Gordon RM, Fitzwater SE (1990) Iron in Antarctic waters. Nature 345:156-157

McKay RML, La Roche J, Yakunin AF, Durnford DG, Geider RJ (1999) Accumulation of ferredoxin and flavodoxin in a marine diatom in response to Fe. J Phycol 35:510-519

McKay RML, Villareal TA, La Roche J (2000) Vertical migration by Rhizosolenia sp. (Bacillariophyceae): implications for Fe acquisition. J Phycol 36:669-674

McMinn A, Skerratt J, Trull T, Ashworth C, Lizotte M (1999) Nutrient stress gradient in the bottom $5 \mathrm{~cm}$ of fast ice, McMurdo Sound, Antarctica. Polar Biol 21:220-227

McMinn A, Ryan K, Gademann R (2003) Diurnal changes in photosynthesis of Antarctic fast ice algal communities determined by pulse amplitude modulation fluorometry. Mar Biol 143:359-367

Morel F, Rueter JG, Anderson DM, Guillard RRL (1979) Aquil: a chemically defined phytoplankton culture medium for trace metal studies. J Phycol 15:135-141

Morel FMM, Hudson RJM, Price NM (1991) Limitation of productivity by trace-metals in the sea. Limnol Oceanogr 36:1742-1755

Pankowski A, McMinn A (2008) Ferredoxin and flavodoxin in eastern Antarctica pack ice. Polar Biol 31:1153-1165

Pankowski A, McMinn A (2009) Development of immunoassays for the iron regulated proteins ferredoxin and flavodoxin in polar microalgae. J Phycol (in press)

Platt T, Gallegos CL, Harrison WG (1980) Photoinhibition of photosynthesis in natural assemblages of marine phytoplankton. J Mar Res 38:687-701

Price NM, Harrison GI, Hering JG, Hudson RJM, Nirel PMV, Palenik B, Morel FMM (1989) Preparation and chemistry of the artificial algal culture medium Aquil. Biol Oceanogr 6:443-461

Ralph PJ, Gademann R (2005) Rapid light curves: a powerful tool for the assessment of photosynthetic activity. Aquat Bot 82:222-237

Raven JA (1990) Predictions of Mn and Fe use efficiencies of phototrophic growth as a function of light availability for

Editorial responsibility: Max Tilzer,

Konstanz, Germany growth and of C assimilation pathway. New Phytol 116: $1-18$

Ryan KG, Ralph P, McMinn A (2004) Acclimation of Antarctic bottom-ice algal communities to lowered salinities during melting. Polar Biol 27:679-686

Schreiber U (2004) Pulse-Amplitude-Modulation (PAM) fluorometry and saturation pulse method: an overview. In: Papageorgiou GC, Govindjee G (eds) Chlorophyll fluorescence: a signature of photosynthesis. Kluwer Academic Publishers, Dordrecht, p 279-319

> Sedwick PN, DiTullio GR, Mackey DJ (2000) Iron and manganese in the Ross Sea, Antarctica: seasonal iron limitation in Antarctic shelf waters. J Geophys Res C 105: 11321-11336

Shaked Y, Kustka AB, Morel FMM (2005) A general kinetic model for iron acquisition by eukaryotic phytoplankton. Limnol Oceanogr 50:872-882

Strzepek R, Harrison PJ (2004) Photosynthetic architecture differs in coastal and oceanic diatoms. Nature 431: 689-692

Sunda WG, Huntsman SA (1995) Iron uptake and growth limitation in oceanic and coastal phytoplankton. Mar Chem 50:189-206

Sunda WG, Huntsman SA (1997) Interrelated influence of iron, light and cell size on marine phytoplankton growth. Nature 390:389-392

Sunda W, Huntsman S (2003) Effect of pH, light, and temperature on Fe-EDTA chelation and Fe hydrolysis in seawater. Mar Chem 84:35-47

Thomas DN, Papadimitriou S (2003) Biogeochemistry of sea ice. In: Thomas DN, Dieckmann G (eds) Sea ice: an introduction to its physics, chemistry, biology and geology. Blackwell Science, Oxford, p 267-302

Timmermans KR, Davey MS, van der Wagt B, Snoek J and others (2001a) Co-limitation by iron and light of Chaetoceros brevis, $C$. dichaeta and C. calcitrans (Bacillariophyceae). Mar Ecol Prog Ser 217:287-297

Timmermans KR, Gerringa LJA, de Baar HJW, van der Wagt B and others (2001b) Growth rates of large and small Southern Ocean diatoms in relation to availability of iron in natural seawater. Limnol Oceanogr 46:260-266

Timmermans KR, van der Wagt B, de Baar HJW (2004) Growth rates, half saturation constants and silicate, phosphate and nitrate depletion in relation to iron availability of four large open ocean diatoms from the Southern Ocean. Limnol Oceanogr 49:2141-2151

van Leeuwe MA, de Baar HJW (2000) Photoacclimation by the Antarctic flagellate Pyramimonas sp. (Prasinophyceae) in response to iron limitation. Eur J Phycol 35:295-303

> van Oijen T, van Leeuwe MA, Gieskes WWC, de Baar HJW (2004) Effects of iron on photosynthesis and carbohydrate metabolism in the Antarctic diatom Chaetoceros brevis (Bacillariophyceae). Eur J Phycol 39:161-171

Vassiliev IR, Kolber Z, Wyman KD, Mauzerall D, Shukla VK, Falkowski PG (1995) Effects of iron limitation on photosystem-II: composition and light utilization in Dunaliella tertiolecta. Plant Physiol 109:963-972

Yousef N, Pistorius EK, Michel KP (2003) Comparative analysis of idiA and isiA transcription under iron starvation and oxidative stress in Synechococcus elongatus PCC 7942 wild-type and selected mutants. Arch Microbiol 180: 4471-4483

Submitted: February 6, 2008; Accepted: November 24, 2008 Proofs received from author(s): January 13, 2009 